\title{
Diversification benefits of commodities: A stochastic dominance efficiency approach ${ }^{*}$
}

\author{
Charoula Daskalaki ${ }^{1}$, George Skiadopoulos ${ }^{2}$, Nikolas Topaloglou ${ }^{3}$ \\ Accepted at the Journal of Empirical Finance
}

\begin{abstract}
We revisit the question whether commodities should be included in investors' portfolios. We employ for the first time a stochastic dominance efficiency (SDE) approach to construct optimal portfolios with and without commodities and we evaluate their comparative performance. SDE circumvents the necessity to posit a specific utility function to describe investor's preferences and it does not impose distributional assumptions on asset returns. We find that commodities provide diversification benefits both in- and out-of-sample. This evidence is stronger when commodity indices which mimic dynamic commodity trading strategies are used. We explain our results by documenting that commodity markets are segmented from the equity and bond markets.

JEL classification: C1, C4, C6, G10, G11

Keywords: Alternative investments, Commodity indices, Market integration, Portfolio choice, Stochastic dominance

\footnotetext{
${ }^{*}$ We are grateful to two anonymous referees for their stimulating, thorough and constructive comments. We would also like to thank Ines Chaieb, George Constantinides, Jens Jackwerth, Olga Kolokolova, Alexandros Kostakis, Kalle Rinne, Raman Uppal and participants at the 2015 International Conference on Computational and Financial Econometrics (London), 2016 Spring Conference of the Multinational Finance Society (Lemesos), Alternative Investments Conference (Monaco), 2016 Energy and Commodity Finance Conference (Paris), 2016 CRETE (Tinos) conference and the University of Crete seminar series for useful discussions and comments. Financial support from the from the Research Centre of the University of Piraeus and the J.P. Morgan Center for Commodities at the University of Colorado Denver via the Commodities Research Fellowship Grant award is gratefully acknowledged. Any remaining errors are our responsibility alone.

${ }^{1}$ Department of Banking and Financial Management, University of Piraeus, GR, chdask@webmail.unipi.gr

${ }^{2}$ School of Economics and Finance, Queen Mary University of London, UK and Department of Banking and Financial Management, University of Piraeus, GR. Also Research Fellow with Cass Business School and Warwick Business School. g.skiadopoulos@qmul.ac.uk,gskiado@unipi.gr

${ }_{3}^{3}$ Department of International and European Economic Studies, Athens University of Economics and Business, GR, nikolas@aueb.gr
} 


\section{Introduction}

Investments in commodities have grown significantly over the last years along with the revived academic interest in the properties of this alternative asset class (for reviews see e.g., Geman, 2005, Erb and Harvey, 2006, Gorton and Rouwenhorst, 2006, Skiadopoulos, 2013). ${ }^{1}$ One of the explanations commonly invoked to explain investors' interest in commodities is their alleged diversification benefits. Commodity returns are expected to have low or negative correlation with the traditional asset classes like bonds and equities returns. Their inclusion in portfolios consisting of traditional asset classes is expected to increase the augmented portfolio’s expected return per unit of risk. Surprisingly though, in the academic literature there is no consensus yet about whether investments in commodities do offer diversification benefits. In this paper, we revisit this open question. Our main contribution is that we deviate from the previous literature and we construct optimal portfolios and assess their performance in a non-parametric way. We manage to do so by employing a stochastic dominance efficiency (SDE) approach which extends the standard stochastic dominance (SD) concept.

SD offers criteria to rank two mutually exclusive investments when compared pairwise (Quirk and Saposnik, 1962, Fishburn, 1964, Hadar and Russell, 1969, Hanoch and Levy, 1969, Levy and Hanoch, 1970, Bawa, 1975). The theoretical attractiveness of SD lies in its nonparametric nature. SD criteria do not require any assumption on the distribution of returns of the two investments under consideration and they are consistent with a general class of preferences in contrast to the popular meanvariance portfolio construction setting. Commonly, first order and second order stochastic dominance criteria (FSD, SSD, respectively) are being used. The FSD criterion is equivalent to using a general utility setting where no restriction on the form of the utility function is placed beyond the requirement

\footnotetext{
1 The total value of commodity investments rose from \$170 billion in July 2007 to $\$ 410$ billion in February 2013 (Croft and Norrish, 2013) accompanied by the 2003-2008 remarkable increase in commodity prices (commodity boom, only the third since 1950).
} 
that it is non-decreasing, i.e., investors prefer more to less. Thus, this criterion is appropriate for both risk averters and risk lovers since the utility function may contain concave as well as convex segments. The SSD criterion adds the assumption of global risk aversion, associated with increasing and concave utility functions (for a characterization of FSD and SSD criteria in terms of Bernoulli utility functions, see also Follmer and Schied, 2011, Section 2.4, who present a general version of these results). ${ }^{2}$ The drawback of the FSD and SSD criteria though is that they can only compare pairwise any two given portfolios. Hence, they cannot be used to test whether a portfolio stochastically dominates every single portfolio because there is an infinite number of alternative portfolios. The concept of SD efficiency (SDE) introduced by Post (2003) and Kuosmanen (2004) circumvents this constraint. It is a direct extension of SD to the case where one can compare the return distribution of any portfolio constructed from a set of assets with another fixed portfolio by exhausting all possible combinations of portfolio weights.

We address our research question both in- and out-of-sample. First, we employ a two-step procedure which uses Scaillet and Topaloglou (2010) SDE test to assess whether a portfolio originated from a traditional asset universe stochastically dominates a portfolio originated from the same asset universe augmented by including commodities. Scaillet and Topaloglou (2010) build on the general distribution definition of SD by relying on Kolmogorov-Smirnov type of tests and they develop consistent statistical tests for SDE at any order for time-dependent data. Next, we conduct our analysis out-of-sample. At any point in time, we construct optimal portfolios based separately on an asset universe comprising traditional asset classes and on an asset universe augmented with commodities by

\footnotetext{
${ }^{2}$ Mean variance optimal portfolio maximizes expected utility only in the case where investor preferences and return distributions obey highly restrictive conditions (i.e. quadratic utility function and/or normally distributed returns, see, e.g., Hanoch and Levy, 1969, Levy, 1992). The mean-variance criterion also corresponds to the maximization of preferences of an investor with specific variational preferences without imposing any assumption on the return distribution (Maccheroni et al., 2006).
} 
employing the Scaillet and Topaloglou (2010) SDE methodology in a rolling window fashion this time. We evaluate the out-of-sample performance of the two optimal portfolios constructed from the two respective asset universes over January 2001-September 2013. We conduct the assessment using the Scaillet and Topaloglou (2010) SDE test and a number of performance measures that take into account deviations from normality as well as transaction costs in line with De Miguel et al. (2009).

To ensure the robustness of our analysis, we implement the SDE approach under the first order and second order SDE criteria (FSDE, SSDE, respectively). In addition, we employ ten first, second and third generation commodity indices as alternative vehicles to invest to the commodity asset class. First generation indices mimic passive commodity futures portfolio strategies where only long positions in the constituent futures are allowed. Second and third generation commodity indices mimic dynamic (long and long/short, respectively) commodity futures portfolio strategies which exploit popular commodity trading signals such as momentum and switches from backwardated to contangoed markets and vice versa (Miffre, 2012); Gorton et al. (2012) find that these dynamic strategies yield significant risk premia, Rallis et al. (2013) document that they outperform passive strategies similar in spirit to the first generation indices and Giamouridis et al. (2014) employ dynamic commodity indices to explore the diversification benefits of commodities. Furthermore, given that we consider dynamic commodity indices, we also employ the Fama-French (1993) size and value factors on top of the S\&P 500 which represents a passive equity strategy. Their use ensures that indices which represent dynamic trading strategies are used in both asset universes and hence it allows a fair comparison of the two asset universes. Finally, we employ alternative stock indices to capture passive and dynamic equity strategies (Russell 2000 and Vanguard value and small-cap, respectively) as well as a momentum factor.

We find that the inclusion of the commodity asset class in portfolios comprising traditional asset classes makes the investor better off both in-sample and out-of-sample. The documented diversification 
benefits of commodities are more pronounced in the case where the investor access commodities via the second and third order generation commodity indices. We explain our results on the outperformance of the augmented by commodities optimal portfolios by documenting that commodity markets are segmented from equity and bond markets using the Campbell and Hamao's (1992) approach. In the case where markets are segmented, assets in different markets are not priced by the same stochastic discount factor. This implies that assets in one market are not spanned by assets in the other markets and hence diversification benefits exist (see e.g., Ferson et al., 1993, Bekaert and Urias, 1996, for the case of mean-variance spanning and DeRoon et al., 2003, for the non mean-variance case).

Related literature. Our paper is related to three strands of literature: portfolio choice with commodities, the SDE literature and the evidence of whether commodity markets are integrated with other markets. Bodie and Rosansky (1980), Fortenbery and Hauser (1990), Ankrim and Hensel (1993), Abanomey and Mathur (1999), Anson (1999), Jensen et al. (2000), Belousova and Dorfleitner (2012) find that the investor is better off by including commodities in her portfolio whereas Cao et al. (2010) find that commodities should not be included in investors' portfolios. These studies are conducted within an insample mean-variance Markowitz (1952) portfolio setting. In contrast, Daskalaki and Skiadopoulos (2011) account for the fact that real-time investors are interested in the out-of-sample performance and commodity futures returns deviate from normality (Gorton and Rouwenhorst, 2006, Kat and Oomen, 2007). They consider alternative utility functions, yet they constrain their analysis to first generation commodity indices and passive equity strategies. They find that commodity investing could be beneficial in-sample, yet these benefits are not preserved out-of-sample just as we document for the first generation commodity indices. ${ }^{3}$ Dai (2009) and Giamouridis et al. (2014) use a dynamic asset

\footnotetext{
${ }^{3}$ Chan et al. (2011), Tang and Xiong (2012), Delatte and Lopez (2013), Silvennoinen and Thorp (2013) and Buyuksahin and Robe (2014) also call the diversification benefits of commodities in question because they report that correlations between commodities and equities have increased over the last decade.
} 
allocation setting and they find that commodities offer diversification benefits in-sample and both inand out-of-sample, respectively; the latter study again documents benefits only in the case where dynamic type of commodity strategies are used. However, all studies require the specification of investor's utility function and make specific modeling assumptions on the asset prices distributional characteristics. To the best of our knowledge, we are the first who explore whether commodities yield diversification benefits by employing an SDE approach; portfolio selection based on SDE is nonparametric.

Regarding the SDE literature, Post (2003), Kuosmanen (2004), Post and Versijp (2007) and Post and Kopa (2013) develop tests for SDE and test whether the market portfolio is efficient from a stochastic dominance perspective; no portfolio construction and evaluation of its performance is undertaken though. In addition, these tests assume that asset returns are identically and independently distributed (i.i.d.); the empirical evidence does not support this assumption. Hodder et al. (2015) is the closest to our study from a SDE portfolio construction perspective. ${ }^{4}$ They construct stock portfolios that are SSDE over the CRSP all share index and they evaluate their out-of-sample performance assuming that asset returns are i.i.d. Scaillet and Topaloglou (2010) SDE methodology is more general than the previous SDE methodologies in that it does not assume that asset returns are i.i.d. Furthermore, it allows for a stronger definition of SDE allowing to test for global SDE. According to the previous studies, a portfolio is defined to be SD efficient if and only if it is not stochastically dominated by any other portfolio that can be constructed from a given asset universe for any given SDE criterion under consideration; this definition may give rise to multiple SD efficient portfolios though. Scaillet and Topaloglou (2010) use a stronger version of stochastic dominance efficiency where a portfolio is defined

\footnotetext{
${ }^{4}$ Meyer et al. (2005) use SD criteria in an i.i.d. setting to check whether international portfolios outperform domestic portfolios; certain portfolio weights are assumed in advance and hence comparison is pairwise. In contrast, rather than choosing in advance the portfolio weights, we use the SDE methodology to deliver the optimal weights of the SDE portfolio.
} 
to be SD efficient when it stochastically dominates all other portfolios for any given SDE criterion under consideration. If a portfolio dominates all other portfolios then it is not dominated by any other portfolio, thus it is SD efficient.

Finally, there is mixed evidence on the integration of commodity markets with equity and bond markets. On the one hand, a number of papers document that the standard equity asset pricing factors cannot explain the cross-section of commodity futures returns implying market segmentation (e.g., Bessembinder and Chan, 1992, Erb and Harvey, 2006, Daskalaki et al., 2014, Bakshi et al., 2015). In addition, Bessembinder (1992) and de Roon et al. (2000) find that commodity futures returns are affected by commodity specific variables. Gorton and Rouwenhorst (2006) suggest that the low correlations of commodities with other asset classes could be regarded as evidence for market segmentation. Giampietro et al. (2016) find that the stochastic discount factor prices assets more accurately when commodity-specific factors are considered in conjunction with macro-based factors. On the other hand, Tang and Xiong (2012) and Boons et al. (2014) argue that the financialization of commodity futures tends to integrate equity and commodity markets. Bakshi et al. (2011) and Hong and Yogo (2012) find that there are common variables which predict the commodity futures and the equity returns whereas Asness et al. (2013) document that there are common factors which explain the pooled cross-section of various asset classes including commodities. As a by-product of our analysis, our findings contribute to this ongoing debate.

The remainder of the paper is structured as follows. Section 2 describes the tests for SDE and the construction of optimal portfolios under the SDE criteria, respectively. Section 3 describes the dataset. Sections 4 and 5 present and discuss results from the in-sample and out-of-sample analysis, 
respectively. Section 6 presents the evidence on markets’ segmentation and Section 7 concludes and discusses the implications of our findings.

\section{Stochastic dominance efficiency: The test and portfolio construction}

\subsection{Description of the test}

We describe the Scaillet and Topaloglou (2010) test for SDE. Let the asset returns be described by a strictly stationary process $\left\{\mathbf{Y}_{t}\right\}$ taking values in $R^{n}$. Observations consist of a realization of $\left\{\mathbf{Y}_{t} ; t=\right.$ $1, \ldots, T\}$. We denote by $F(y)$, the continuous cumulative distribution function of $\mathbf{Y}=\left(\mathrm{Y}_{1}, \ldots \mathrm{Y}_{\mathrm{n}}\right)^{\prime}$ at point $\mathbf{y}=\left(\mathrm{y}_{1}, \ldots \mathrm{y}_{\mathrm{n}}\right)^{\prime}$. Let a portfolio consisting of $n$ assets and the vector $\boldsymbol{\lambda}$ of portfolio weights in $L$, where $L=$ $\left\{\boldsymbol{\lambda} \in \mathrm{R}^{\mathrm{n}}: \mathbf{e}^{\prime} \boldsymbol{\lambda}=1\right\}$ with $\mathbf{e}$ being a vector of units. Let $G(z, \lambda ; F)$ denote the cumulative density function of the portfolio return $\lambda^{\prime} \mathbf{Y}$ at portfolio return point $z$ given by

$$
G(z, \lambda ; F):=\int_{R^{n}} I\left\{\lambda^{\prime} u \leq z\right\} d F(u)
$$

where $I\left(\right.$ ) denotes the indicator function taking the value of 1 if $\lambda^{\prime} u \leq z$ and 0 otherwise. Further, define

$$
\begin{aligned}
& J_{1}(z, \lambda ; F):=G(z, \lambda ; F), \\
& J_{2}(z, \lambda ; F) ;=\int_{-\infty}^{z} G(u, \lambda ; F) d u=\int_{-\infty}^{z} J_{1}(u, \lambda ; F) d u
\end{aligned}
$$

The hypothesis for testing SDE of order $j$ ( $j=1$ for first SDE and $j=2$ for second SDE) can be written compactly as:

$$
\begin{aligned}
& H_{0}^{j}: J_{j}(z, \tau ; F) \leq J_{j}(z, \lambda ; F) \quad \text { for all } z \in R \text {, and for all } \lambda \in L, \\
& H_{1}^{j}: J_{j}(z, \tau ; F)>J_{j}(z, \lambda ; F) \quad \text { for some } z \in R \text {, and for some } \lambda \in L .
\end{aligned}
$$


Under the null hypothesis $H_{0}^{j}$, there is no portfolio $\lambda$ formed from the set of assets that dominates the benchmark $\tau$ at any order $j$, i.e. the benchmark portfolio $\tau$ is SDE. In this case, the function $J_{j}(z, \tau ; F)$ is always lower than the function $J_{j}(z, \lambda ; F)$ for any possible portfolio $\lambda$ constructed from the set of alternative assets for any point $z$. Under the alternative hypothesis $H_{1}^{j}$, we can construct a portfolio $\lambda$ that for some points $z$, the function $J_{j}(z, \tau ; F)$ is greater than the function $J_{j}(z, \lambda ; F)$, i.e. the benchmark portfolio $\tau$ is not SDE.

We test the null hypothesis by employing the Scaillet and Topaloglou (2010) test which uses a $\hat{S}_{j}$ Kolmogorov-Smirnov type test statistic of order $j$

$$
\hat{S}_{j}:=\sqrt{T} \sup _{z, \lambda}\left[J_{j}(z, \tau ; \hat{F})-J_{j}(z, \lambda ; \hat{F})\right]
$$

where $\hat{F}$ is the empirical distribution of $F$. We reject $H_{0}^{j}$ if $\hat{S}_{j}>c_{j}$, where $c_{j}$ is some critical value (for the test properties, see Scaillet and Topaloglou, 2010). We provide details on the implementation of the test under the first and second order SDE criteria in Appendix A.1 and A.2.

Three remarks are in order regarding the test under consideration. First, the test builds on the distribution definition of SD which has a nice economic interpretation. FSD and SSD can be characterized in terms of Bernoulli utility functions as has already been discussed in the introduction. In particular, under the stated above null hypothesis, FSD is equivalent to $E[U(\tau)] \geq E[U(\lambda)]$ for any nondecreasing monotonic utility function $U(z)$ of $z$, i.e., $U^{\prime}(z)>0$ and SSD is equivalent to $E[U(\tau)] \geq E[U(\lambda)]$ for any non-decreasing monotonic and concave utility function of z, i.e., $U^{\prime}(z)>0$ and $U^{\prime \prime}(z)<0$ where the expectation operator for $E[U(\tau)]$ and $E[U(\lambda)]$ is formed with respect to the cumulative distribution functions of portfolios $\tau$ and $\lambda$ returns, respectively. Second, rejection of the null 
hypothesis does not necessarily imply that there is a portfolio that stochastically dominates the benchmark portfolio.

Third, given that the distribution of $\hat{S}_{j}$ is not known, we calculate the $p$-value corresponding to $c_{j}$ by bootstrap. We use the Hall et al. (1995) block bootstrap method which does not assume that asset returns are identically and independently distributed (i.i.d.); this is in contrast to SDE tests employed by the previous literature which rely on the i.i.d. assumption. The method divides the original data into blocks. Blocks are resampled with replacement from the original data to mimic the time dependent structure of the original data. The block size equals the sample size once it is raised to the third power. We generate $R=500$ bootstrap samples. We define the $p$-value $p_{j}^{*}:=P\left[S_{j}^{*}>\hat{S}_{j}\right]$, where $S_{j}^{*}$ is the test statistic corresponding to each bootstrap sample. The $p$-value is approximated by

$$
\tilde{p}_{j}=\frac{1}{R} \sum_{r=1}^{R} I\left\{\tilde{S}_{j}^{r}>\hat{S}_{j}\right\}
$$

where the $\widetilde{S}_{j}^{r}$ is the test statistic corresponding to the $r$ th bootstrapped sample. Proposition 3.1 in Scaillet and Topaloglou (2010) ensures that the power of the test is preserved under the bootstrapped critical values.

\subsection{Portfolio construction}

We describe how we form the SDE portfolio (if it exists) in the case where the null hypothesis is rejected. Portfolio $\lambda$ is termed to dominate a benchmark portfolio $\tau$ under the first order and second order stochastic dominance efficiency criteria (FSDE, SDEE) respectively, if it solves the following maximization problem with respect to $\lambda$

$$
\max _{z, \lambda}[G(z, \tau ; F)-G(z, \lambda ; F)]
$$




$$
\max _{z, \lambda}\left[\int_{-\infty}^{z} G(u, \tau ; F) d u-\int_{-\infty}^{z} G(u, \lambda ; F) d u\right]
$$

The resulting portfolio is also termed efficient. Therefore, a portfolio is defined to be efficient when it stochastically dominates all other portfolios constructed from a given asset universe for any given SDE criterion under consideration. ${ }^{5}$ Equations (5) and (6) highlight the difference between the standard SD and the SDE concepts. In the latter case, the dominant portfolio is derived by taking the maximum over all possible portfolios and returns whereas in the former case two given portfolios are being compared. Figures 1 and 2 display the FSDE and SSDE concepts. Note that FSDE is a sufficient but not a necessary condition for SSDE.

Hadar and Russell (1969) and Bawa (1975) show that FSD (SSD) amounts to choosing the investment that maximizes investor's expected utility assuming that investors preferences are characterized by non-satiation (non-satiation and risk aversion). Given these theoretical results, the optimal portfolio is the SD efficient portfolio derived from the solution of equations (5) and (6). From an implementation point of view, one needs to search for the portfolio weights so that the optimal portfolio will yield a cumulative distribution function that solves equations (5) and (6), i.e. a portfolio that maximizes the distance between the two cumulative distribution functions (FSDE) and the distance between the integrals of the cumulative distribution functions (SSDE) for any given return. To this end, we need to choose a benchmark portfolio as well as the size of the historical sample of asset returns. Appendix A.3 provides further details.

\section{The data}

\footnotetext{
${ }^{5}$ Notice that Markowitz (1952) concept of efficient portfolio differs from the efficient one under the stochastic dominance efficiency criterion. The latter is the optimal portfolio whereas the former may not be the optimal one even if Markowitz assumptions hold; from the set of efficient à la Markowitz portfolios, only one will be the optimal for a given investor if Markowitz assumptions hold.
} 
We use data on monthly closing prices of a number of indices obtained from Bloomberg. We employ the S\&P 500 Total Return Index, Barclays U.S. Aggregate Bond Index and the one-month Libor rate to proxy the traditional asset universe, i.e. the equity market, the bond market and the risk-free rate, respectively. To access the commodity asset class, we use various widely-followed commodity futures indices. We use first, second and third generation commodity indices. This is in contrast to the previous literature that uses only first generation commodity indices.

The first generation indices are long-only fully-collateralized investments. They reflect a strategy consisting of the shortest maturity commodity futures contracts which rolls to the subsequent month’s contracts as the lead or front month expires. We consider the S\&P Goldman Sachs Commodity Index (S\&P GSCI), the Dow Jones-UBS Commodity Index (DJ UBSCI) and the Deutsche Bank Liquid Commodity Index (DBLCI) as representatives of the first generation indices. By construction, the first generation indices provide positive roll returns only in the case that the term structure of commodity futures prices is in backwardation. However, given that futures markets switch from backwardation to contango and vice versa, the first generation indices perform poorly in contangoed markets. In addition, the contracts close to expiration tend to be more contangoed and volatile and as a result they experience a negative roll yield.

The second generation indices take these facts into account and they attempt to minimize the harmful impact of contangoed markets by investing into sufficiently liquid contracts which are further out in the term structure of commodity futures prices. We consider the JP Morgan Commodity Curve Index (JPMCCI), the Deutsche Bank Liquid Commodity Index-Optimum Yield (DBLCI-OY), the Morningstar Long/Flat Commodity Index (MSDILF) and the Morningstar Long-Only Commodity Index (MSDIL) as representatives of the second generation indices. 
Finally, the third generation indices allow taking both long and short positions. We consider the Morningstar Short/Flat Commodity Index (MSDISF), the Morningstar Short-Only Commodity Index (MSDIS) and the Morningstar Long/Short Commodity Index (MSDILS) as representatives of the third generation indices. Appendix B provides details on the construction of these third generation indices. To ensure that both asset universes employ indices which represent dynamic trading strategies, we use also the Fama-French (1993) equity factors to proxy the equity market, i.e. the value and the size factors. We obtain these factors from Kenneth French's website. Table 1 describes the set of equity, bond and commodity indices employed in this study.

The dataset spans January 1990 to September 2013 with the exception of DJ-UBSCI that covers the period January 1991 to September 2013 due to data availability constraints. Table 2 reports summary statistics regarding the performance of the employed indices over this period. We can see that the monthly average return on commodity indices is higher than that of stocks and bonds and in most cases it exhibits greater standard deviation. With a few exceptions, the Sharpe ratio is considerably greater for bonds and stocks than commodity indices. The reported evidence is consistent with previous studies, which document that the stand-alone risk-adjusted performance of commodity indices is inferior to other asset classes (see e.g., Jensen et al., 2000, Daskalaki and Skiadopoulos, 2011).

Finally, we obtain data on a set of variables documented to forecast returns in equity and bond markets. We obtain data on the dividend yield on MSCI World, the junk bond premium (or default spread, defined as the excess of the yield on long-term BAA corporate bonds rated by Moody's over the yield on AAA-rated bonds), the term spread (defined as the difference between the Aaa yield and the one-month bill rate) and the Baltic Dry Index from Bloomberg. We obtain data on the 3-month Treasury Bill, Industrial Production, and money supply from the Board of Governors of the Federal Reserve System (U.S.). 


\section{In-sample Analysis: Results and discussion}

In this section, we test in-sample whether the inclusion of commodities in the asset universe makes the investor better off compared to the case where the asset universe consists of only traditional asset classes (stocks, bonds and cash). We proceed in two steps. In the first step, we define the benchmark portfolio $\tau$ to be the S\&P 500 index. Then, we apply the Scaillet and Topaloglou (2010) test to assess the null hypothesis that the S\&P 500 is SD efficient relative to any $\lambda$ portfolio to be formed based on the constrained asset universe for every return level. In the second step, we choose the benchmark portfolio to be the one dictated by the first step. This would be the S\&P 500 in the case the null hypothesis is not rejected or the portfolio based on the constrained asset universe if the null is rejected. If there are many portfolios consisting of these three asset classes that dominate the S\&P 500, we take as optimal the one that maximizes the distance from the cumulative distribution function of the S\&P. This maximum distance portfolio dominates all other portfolios and is not dominated by any other portfolio, thus it is SD efficient. Then, we re-apply the Scaillet and Topaloglou test to assess the null hypothesis that the redefined benchmark portfolio is efficient relative to any $\lambda$ portfolio to be formed based on the augmented with commodities asset universe for every return level. We apply the two-step testing procedure for FSDE and SSDE criteria, separately.

We conduct the analysis using each one of the commodity indices under scrutiny separately. We access investment in commodities via the first (S\&P GSCI, DJ-UBS CI, DBLCI), second (JPMCCI, DBLCI-OY, MSDILF, MSDIL) and the third generation commodity indices (MSDISF, MSDILS, MSDIS), separately. The test statistics and respective $p$-values (within parentheses) for the null hypothesis that the optimal portfolio based on the traditional asset universe (stocks, bonds and cash) augmented with commodities stochastically dominates the optimal portfolio based on the traditional 
asset universe. In case the null hypothesis is rejected, this would imply that the benchmark portfolio is not optimal and hence commodities may offer diversification benefits. We consider two in-sample periods. The first is the full sample period January 1990 to December 2013 and the second is January 1990 -December 2000. The latter is the period we retain as a starting point to conduct the out-of-sample analysis over January 2001 - September 2013 in Section 5.

Table 3 reports the FSDE and SSDE test statistics and respective $p$-values for the null hypothesis that a set of benchmark assets consisting of stocks, bonds and the risk-free asset is SD efficient versus the benchmark asset universe augmented with the commodity asset class over the period January 1990 to September 2013. Investors access investment in commodities via the first generation indices (S\&P GSCI, DJ-UBS CI, DBLCI), second generation indices (JPMCCI, DBLCI-OY, MSDILF, MSDIL) and third generation indices (MSDISF, MSDILS, MSDIS), separately. Panel A reports results for the case where the benchmark asset universe consists of the S\&P 500 Total Return Index, Barclays Aggregate Bond Index and one-month LIBOR rate. Panels B and C report results when the benchmark set includes dynamic equity indices in lieu of the S\&P 500, i.e. the Fama-French (1993) size factor (Small minus Big, SMB) and the value factor (High minus Low, HML), respectively. The use of the Fama-French (1993) factors ensures a fair comparison of the traditional asset classes universe with the augmented with commodities one. This is because in both asset universes, we use indices that represent dynamic trading strategies.

We can see that the null hypothesis can be rejected in almost all cases at $10 \%$ significance level, but the S\&P GSCI when the SMB factor is considered. This evidence suggests that the performance of traditional portfolios, consisting of stocks, bonds and cash, can be significantly improved by investing in commodities. In fact, we find that there is a portfolio that consists of stocks, bonds, cash and 
commodities which is SDE. We obtain qualitatively similar results over January 1990 to December 2000. Results are not reported due to space limitations.

\section{Diversification benefits: Out-of-sample analysis}

In Section 4, we found that commodities may yield diversification benefits in-sample. In this section, we examine whether commodities provide diversification benefits out-of-sample, too. We form optimal portfolios separately for two asset universes, one that includes “traditional” asset classes (i.e. equities, bonds, risk-free asset) and an "augmented” one that also includes commodity indices. At any point in time (every month in our case), we apply the two-step Scaillet and Topaloglou (2010) methodology described in Section 4 under the under the FSDE and SSDE efficient criteria separately by allowing for short selling. Every month, the described procedure delivers two optimal portfolios for the two respective asset universes. We repeat the two steps throughout our sample in a rolling window fashion. Assume that the dataset consists of $T$ (in our case, $T=285$ ) monthly observations for each asset and $K$ is the size of the employed rolling window used for the calculation of the portfolio weights. Standing at each month $t$, we use the previous $K$ observations to estimate the SDE portfolio weights (i.e. weights that maximize expected utility). Next, we use the estimated weights to compute the out-of-sample realised return over the period $[t, t+1]$. We repeat this process by incorporating the return for the next period and ignoring the earliest one, until the end of the sample is reached. This approach allows deriving a series of monthly out-of-sample optimal portfolio returns. Then, we use the time series of realised portfolio returns to evaluate the out-of-sample performance of the two derived optimal portfolios. 
We choose the size of the rolling window $K=120$. This delivers January 1990 -December 2000 as the starting time interval for the estimation of optimal portfolio weights and January 2001 December 2013 as the out-of-sample period.

\subsection{Performance evaluation}

We compare the out-of-sample performance of the two optimal portfolios based on the respective asset universes by using non-parametric and parametric tests. First, we use the Scaillet and Topaloglou (2010) non-parametric test to test the null hypothesis that the optimal portfolio based on the augmented asset universe (stocks, bonds, cash and commodities) stochastically dominates the traditional asset universe. The alternative hypothesis is that the augmented asset universe based portfolio does not stochastically dominate the traditional asset universe based optimal portfolio. ${ }^{6}$ We test the null hypothesis by using first order and second order stochastic dominance criteria.

Next, in line with DeMiguel et al. (2009), Kostakis et al. (2010) and Daskalaki and Skiadopoulos (2011), we employ four commonly used parametric performance measures: the Sharpe ratio (SR), opportunity cost, portfolio turnover and a measure of the portfolio risk-adjusted returns net of transaction costs. These performance measures, yet parametric, will supplement the evidence obtained

\footnotetext{
${ }^{6}$ Note that in contrast to the way we formulate the null hypothesis in the in-sample analysis' case, now we choose to formulate the null hypothesis in the reverse way. Such a formulation is feasible from a computational perspective since in the out-of-sample case we compare two portfolios pairwise. It has the advantage that acceptance of the null would mean that the augmented portfolio is SD dominant. This interpretation leaves no ambiguity. In contrast, if we had formulated the null hypothesis as in the in-sample case, rejection of the null would not necessarily mean that the augmented portfolio is dominant; it may be the case that the two portfolios could not be assessed under a given stochastic dominance criterion. Unfortunately, such a hypothesis formulation is not possible in the in-sample case. This is because for the SD efficiency tests, the existing methodologies can only test the efficiency of a given benchmark portfolio relative to portfolios which can be constructed from the augmented asset universe.
} 
from the previously discussed non-parametric SDE measure; the greater the value of each one of these measures, the greater the diversification benefits of commodities. To fix ideas, let a specific strategy denoted by $c$. The estimate $\widehat{S R}_{c}$ of the strategy's $S R_{c}$ is defined as the fraction of the sample mean of out-of-sample excess returns $\hat{\mu}_{c}$ divided by their sample standard deviation $\hat{\sigma}_{c}$, i.e.

$$
\widehat{S R}_{c}=\frac{\hat{\mu}_{c}}{\hat{\sigma}_{c}}
$$

To test whether the SRs of the two optimal portfolios based on the traditional and augmented with commodities asset universes, are statistically different, we use Memmel's (2003) statistic; the null hypothesis is that the SRs of the two strategies are equal. The use of SR is in line with the finance industry practice even though it can lead to misleading conclusions (e.g., Rothschild and Stiglitz, 1970, Section IV).

Next, we use the concept of opportunity cost (Simaan, 1993) to assess the economic significance of the difference in performance of the two optimal portfolios, respectively. Denote by $r_{w c}, r_{n c}$ the optimal portfolio realized returns obtained by an investor with the augmented investment opportunity set that includes commodities and the investment opportunity set restricted to the traditional asset classes, respectively. The opportunity $\operatorname{cost} \theta$ is defined to be the return that needs to be added (or subtracted) to the portfolio return $r_{n c}$ so that the investor becomes indifferent (in utility terms) between the two strategies imposed by the different investment opportunity sets, i.e.

$$
E\left[U\left(1+r_{n c}+\theta\right)\right]=E\left[U\left(1+r_{w c}\right)\right]
$$

Therefore, a positive (negative) opportunity cost implies that the investor is better (worse) off in case of an investment opportunity set that allows commodity investing. Notice that the opportunity cost takes into account the entire probability density function of asset returns and hence it is suitable to evaluate strategies even when the assets return distribution is not normal. To calculate the opportunity cost, we 
use an exponential and a power utility function alternatively and we employ alternative values of investor's risk aversion.

The portfolio turnover (PT) is computed so as to get a feel of the degree of rebalancing required to implement each one of the two strategies. For any portfolio strategy $c$, the portfolio turnover $P T_{c}$ is defined as the average absolute change in the weights over the $T-K(T-120)$ rebalancing points in time and across the $N$ available assets, i.e.

$$
P T_{c}=\frac{1}{T-K} \sum_{t=1}^{T-K} \sum_{j=1}^{N}\left(\left|w_{c, j, t+1}-w_{c, j, t+}\right|\right)
$$

where $w_{c, j, t}, w_{c, j, t+1}$ are the derived optimal weights of asset $j$ under strategy $c$ at time $t$ and $t+1$, respectively; $w_{c, j, t+}$ is the portfolio weight before the rebalancing at time $t+1$; the quantity $\left|w_{c, j, t+1}-w_{c, j, t+}\right|$ shows the magnitude of trade needed for asset $j$ at the rebalancing point $t+1$. The $P T$ quantity can be interpreted as the average fraction (in percentage terms) of the portfolio value that has to be reallocated over the whole period.

Finally, we also evaluate the two investment strategies under the risk-adjusted, net of transaction costs, returns measure proposed by DeMiguel et al. (2009). This metric provides an economic interpretation of the PT; it shows how the proportional transaction costs generated by the portfolio turnover affect the returns from any given strategy. To fix ideas, let $p c$ be the proportional transaction cost and $r_{c, p, t+1}$ the realized portfolio return at $t+1$ (before rebalancing). The evolution of the net of transaction costs wealth $N W_{c}$ for strategy $c$, is given by:

$$
N W_{c, t+1}=N W_{c, t}\left(1+r_{c, p, t+1}\right)\left[1-p c \times \sum_{j=1}^{N}\left(\left|w_{c, j, t+1}-w_{c, j, t+}\right|\right)\right]
$$

Therefore, the return net of transaction costs is defined as 


$$
R N T C_{c, t+1}=\frac{N W_{c, t+1}}{N W_{c, t}}-1
$$

The return-loss measure is calculated as the additional return needed for the strategy with the restricted opportunity set to perform as well as the strategy with the expanded opportunity set that includes commodity futures. Let $\mu_{w c}, \mu_{n c}$ be the monthly out-of-sample mean of $R N T C$ from the strategy with the expanded and the restricted opportunity set, respectively, and $\sigma_{w c}, \sigma_{n c}$ be the corresponding standard deviations. Then, the return-loss measure is given by:

$$
\text { return }- \text { loss }=\frac{\mu_{w c}}{\sigma_{w c}} \times \sigma_{n c}-\mu_{n c}
$$

A positive return-loss measure indicates that the investor is better off when commodities are included in investor's portfolio. To calculate $N W_{c, t+1}$, we set the proportional transaction cost pc equal to 50 basis points per transaction for stocks and bonds (for a similar choice, see DeMiguel et al., 2009), 35 basis points for the commodity indices (based on discussion with practitioners in the commodity markets), and zero for the risk-free asset. ${ }^{7}$

\subsection{Results and discussion}

\footnotetext{
${ }^{7}$ To ensure the robustness of the obtained results, we have also employed alternative values for the level of transaction costs for equities. The CME report (2016) quantifies the cost of replicating the total return of the S\&P 500 index and concludes that the round-trip transaction costs range from 2.9 basis points for index futures to between 6.5 and 7.5 basis points for ETFs. We recalculate the return-loss measure by considering the cases where the transaction costs for equities equal these values. The results remain qualitatively similar, i.e. the return loss metric remains positive which confirms the out-of-sample superiority of the portfolios that include commodity indices, even after deducting the incurred transaction costs. Regarding the transaction costs for commodities, Szakmary et al. (2010) provide indirect estimates for commodities by relying on a formula which the authors develop. The average $p c$ value for commodity futures is $10.65 \mathrm{bps}$ and the median value is 8.64 bps. Given that a commodity index may be viewed as an average commodity, the employed value of 35 bps for the $p c$ of a commodity index does not bias results in favor of commodities.
} 
This section discusses the results on the out-of-sample performance of the traditional asset classes portfolios and the augmented with commodities ones. Table 4 reports the Scaillet and Topaloglou (2010) test statistics and p-values (within parentheses). We employ first order and second order stochastic dominance criteria (FSD, SSD, respectively). Panel A reports results for the case where the benchmark asset universe consists of the S\&P 500 Total Return Index, Barclays Aggregate Bond Index and one-month LIBOR rate. Panels B and C report results when the benchmark set includes dynamic equity indices in lieu of the S\&P 500, i.e. the Fama-French (1993) size factor (Small minus Big, SMB) and the value factor (High minus Low, HML), respectively. We can see that we cannot reject the null hypothesis, i.e. we document that the augmented with commodities optimal portfolios stochastically dominate the optimal portfolios based on the traditional asset universe. This holds for all employed commodity and equity indices under both FSDE and SSDE criteria. Thus, under the SD setting, we extend the in-sample evidence on the diversification benefits provided by commodities.

Next, we compare the out-of-sample performance of the two optimal portfolios using the four standard parametric measures of performance. Note that the SDE optimization algorithm assigns nonzero weights to the various commodity indices. In most cases, the average weight exceeds $70 \%$ for either the FSDE or the SSDE criterion. Table 5 reports results for each one of the four performance measures. Panels A and B report results for the cases where portfolio weights are calculated by FSDE and SSDE criteria, respectively. In the case of opportunity cost, we assume various levels of (absolute/relative) risk aversion (ARA, RRA=2, 4, 6) for the individual investor. To assess the statistical significance of the superiority in SRs, we also report the p-values of Memmel's (2003) test within parentheses.

In the case of the first generation indices, results are mixed depending on the employed performance measure. We can see that the optimal portfolios formed based on the augmented 
investment opportunity set yield greater SRs than the corresponding portfolio strategies based on the traditional investment opportunity set. However, the $p$-values of Memmel's (2003) test indicate that the differences in SRs are not statistically significant. Regarding the opportunity cost, we can see that in some cases this is positive and in some other cases it is negative. This implies that the investor is not always better off when the augmented investment opportunity set is considered. Furthermore, with the exception of S\&P GSCI, the portfolios that include only the traditional asset classes induce more portfolio turnover compared with the ones that include commodities. Finally, we can see that the returnloss measure that takes into account transaction costs is positive.

At this point two remarks are in order. First, the mixed evidence on the existence of diversification benefits of commodities across the various performance measures extends the evidence in Daskalaki and Skiadopoulos (2011) who document that there are no diversification benefits in the case of the first generation commodity indices where a passive equity index (S\&P 500) is used. The two papers are not directly comparable though since they cover different periods of time and they differ in the implementation process (e.g. the size of the employed rolling windows). Second, the difference in the results between the SD setting and the parametric performance measures regarding the first generation indices can be attributed to the inherent assumptions of the two approaches. Note that the SD setting makes no assumptions on the distribution of asset returns and it is consistent with a very general family of utility functions whereas the employed parametric performance measures either focus on mean and variance or they assume a specific utility function and specific risk aversion coefficients.

On the other hand, in the case of the second and third generation commodity indices, the parametric performance measures indicate that there is strong evidence on the diversification benefits of commodities. We can see that the optimal portfolios formed based on the augmented investment opportunity set yield greater SRs than the corresponding portfolio strategies based on the traditional 
investment opportunity set. In contrast to the first generation indices, the $p$-values of Memmel's (2003) test show that the differences in SRs are statistically significant. The differences in SRs are statistically significant when investments in commodities are accessed by any commodity index but MSDIS. Regarding the opportunity cost, we can see that this is positive in all cases which implies that the investor is better off when the augmented investment opportunity set is considered. In most cases, the opportunity cost decreases as the risk aversion increases, yet it still remains sizeable ranging up to $7 \%$ and $7.9 \%$ for the second and third generation indices, respectively. This implies that the investor who does not include commodities is not as happy as the investor who has included commodities and this loss in happiness can be offset only by offering her a 7\% (7.9\%) return on top of the constrained portfolio's return. Notice that the fact that MSDIS constitutes an exception when the SR is being used highlights the superiority of commodity indices that mimic dynamic trading strategies; MSDIS is a passive short index. Finally, we can see that the return-loss measure that takes into account transaction costs is positive which confirms the out-of-sample superiority of the portfolios that include commodity indices, even after deducting the incurred transaction costs. These findings hold both for the cases where portfolios are constructed by FSDE and SSDE criteria.

Table 6 and Table 7 report results in the case where investors access investment in equities via dynamic indices, i.e. the Fama-French (1993) value factor (High minus Low, HML) and the size factor (Small minus Big, SMB), respectively. We can see that in the case where we replace the S\&P 500 with the size factor, the results do not change compared to the case where we proxy the equities asset class with the S\&P 500, i.e. commodities should be included in investors' portfolios when second and third generation commodity indices are used. Moreover, we can see that in the case where we replace the S\&P 500 with the value factor, commodities are beneficial to investors even for the first generation commodity indices. 
To sum up, the employed parametric performance measures indicate that the diversification benefits of commodities are more pronounced when the investor accesses commodities via the second and third generation commodity indices which exploit signals such as momentum and changes in the term structure signals and/or allow for short positions. This is in accordance with the evidence in Giamouridis et al. (2014) on the performance of dynamic commodity strategies in a portfolio setting; yet, their results are subject to their modelling assumptions. One possible additional explanation regarding the weaker results of the first generation commodity indices is that the monthly rolling process followed by these indices may deteriorate the commodity index performance (Mou, 2011).

\subsection{Further robustness tests}

In this section, we perform further tests to assess the robustness of the results reported in section 5.2. To this end, we consider additional indices in the traditional asset universe. First, we repeat the analysis where we proxy the equity asset class by including both the S\&P 500 and a dynamic equity index. Note that the SMB and HML indices have lower annualized Sharpe ratios (-0.088 and 0.111, respectively) compared to the S\&P 500 (0.419). Thus, replacing S\&P500 with SMB or HML may favor commodities. To ensure the robustness of our results, we include both the S\&P 500 and the HML index

in the traditional asset universe; we choose the HML because its risk-adjusted performance is superior to SMB index. In addition, we further augment the traditional asset universe with an equity momentum factor in line with Giamouridis et al. (2014). We obtain the momentum factor from Kenneth French's website (its Sharpe ratio equals 0.189).

Table 8 reports the results on the out-of-sample performance of the traditional asset classes portfolios and the augmented with commodities ones. The traditional investment opportunity set includes the S\&P 500 Equity Index, the HML dynamic index, the Momentum factor, the Barclays US 
Aggregate Bond Index and the 1-month LIBOR rate. We can see that the optimal portfolios formed based on the investment opportunity set that also includes commodities yield statistically significant greater SRs than the corresponding portfolio strategies based on the traditional investment opportunity set. Regarding the opportunity cost and the return loss metric, we can see that they are positive in all cases which further confirms the superiority of the commodity investment. These findings hold regardless of whether portfolio weights are constructed either by the FSDE or the SSDE criteria.

Second, we repeat the analysis where we proxy the equity asset class by including Russell 2000 equity index, Vanguard value and Vanguard small-cap index funds in lieu of the S\&P 500 and FamaFrench factors. It is worth stating that the risk-adjusted performance of the Vanguard index funds is superior to that of the Fama-French factors and this would pose a stricter hurdle for commodities to pass. In particular, the annualized Sharpe ratios equal 0.170 and 0.235 for the Vanguard value and the Vanguard small-cap indices, respectively, whereas the respective figures for HML and SMB are 0.111 and -0.088. On the other hand, Russell 2000 index is a well-followed equity index with Sharpe ratio equal to 0.315 , lower than that of S\&P500 (0.419). Table 9 reports the results when the traditional set includes the Russell 2000 Index, the Vanguard value and small index funds, the Barclays US Aggregate Bond Index and the 1-month LIBOR rate. We can see that all performance measures indicate that there are still diversification benefits for commodities, albeit reduced compared to the case where we proxy the equities asset class by the S\&P 500 and the Fama-French factors. ${ }^{8}$

\section{Why do investments in commodities offer diversification benefits?}

\footnotetext{
${ }^{8}$ Note that for both alternative traditional asset universes, in the out-of-sample setting, we cannot reject the null hypothesis that the optimal portfolio based on the augmented asset universe (stocks, bonds, cash and commodities) stochastically dominates the traditional asset universe. This holds in all cases under both FSDE and SSDE criteria. Results are not reported due to space limitations.
} 
In this section, we investigate the reason of the outperformance of the augmented portfolios which include commodities versus the ones which do not as documented in the previous sections. To this end, we test whether the commodity market is integrated/ segmented with the equity and bond market. Market integration is defined to be the case where financial assets that trade in different markets yet they have identical risk characteristics, will have identical expected returns (Bessembinder, 1992, Campbell and Hamao, 1992). Hence, in the case of market integration, there is a common stochastic discount factor which prices the various asset classes. In this case, commodity returns would be spanned by the traditional asset classes' returns and there will be no diversification benefits (see, e.g., Ferson et al., 1993, Bekaert and Urias, 1996, DeRoon et al., 2003).

We follow Campbell and Hamao (1992) approach to test for market integration. Let a $K$-factor asset pricing model

$$
R_{i, t+1}=E_{t}\left(R_{i, t+1}\right)+\sum_{k=1}^{K} \beta_{i k} f_{k, t+1}+e_{i, t+1}
$$

where $R_{i, t+1}$ denotes the excess return on asset $i$ held from time $t$ to time $t+1, f_{k, t+1}$ the $k$ th factor realization, $\beta_{i k}$ the factor loading with respect to the $k$ th factor and $e_{i, t+1}$ the error term. Equation (13) maps to an expected return-beta representation (Cochrane, 2005)

$$
E_{t}\left(R_{i, t+1}\right)=\sum_{i=1}^{K} \beta_{i k} \lambda_{k t}
$$

where $\lambda_{k t}$ is the market price of risk for the $k$ th factor at time $t$. The time variation in the $k$ th factor market price of risk is modeled as

$$
\lambda_{k t}=\sum_{n=1}^{N} \theta_{k n} X_{n t}
$$

where there is a set of $N$ predictors $X_{n t}, n=1,2, \ldots, N$. Assuming that (1) markets are integrated, i.e. they have the same prices of risk, and (2) the time variation in expected returns stems from time variation in 
the prices of risk, equations (14) and (15) imply that predictor variables that drive prices of risk should be the same across assets. ${ }^{9}$ Therefore, evidence that the predictors of the price of risk differ across asset classes would imply that the market price of risk is not the same across assets and hence markets are segmented.

We use predictors which have been documented to predict equity and bond markets returns: the dividend yield, the yield on the three-month Treasury bills, the default spread (Bessembinder and Chan, 1992), the term spread (Fama and French, 1989), the industrial production growth (Fama, 1990), the money supply growth (Chen, 2007), and the growth in the Baltic Dry Index (Bakshi et al., 2011). Table 10 presents the evidence on the forecastability of the asset returns during the period 1999-2013; the choice of the period is consistent with the choice of the out-of-sample period in Section 5.1 where we evaluate the portfolios' out-of-sample performance. We can see that the S\&P 500 equity index can be predicted by the T-bills, the term spread and the growth in the Baltic Dry Index. The Barclays Bond index can be predicted by the T-bills, the dividend yield and the term spread. On the other hand, these predictors do not forecast commodity indices returns. This evidence is also supported by the F-statistic and the respective $p$-values: the hypothesis that all coefficient estimates equal to zero can be rejected only for the traditional asset classes, i.e. the S\&P 500 equity index and the Barclays Bond Index.

Our results show that commodity returns cannot be forecasted by variables that predict stock and bond market returns. This suggests that the price of risk is driven by different predictors across the various asset classes which in turn implies that the prices of risk differ. As a result, commodity markets are segmented from equity and bond markets and hence the inclusion of commodities in investors' portfolios is expected to yield diversification benefits. Note that the market integration test offers a statistical setting on top of the economic significance setting applied in the previous sections to assess

\footnotetext{
${ }^{9}$ Ferson and Harvey (1991) document that assumption (2) holds; expected returns are driven by time variation of prices of risk rather than time variation of betas.
} 
whether commodities may offer diversification benefits. In addition, the test is applied to the full sample and hence the obtained results are meant to be discussed in light of the in-sample evidence provided in Section 4.

A remark is in order at this point. Our results do not contradict the previous literature which documents that commodities can be predicted by various macroeconomic factors. Most studies employ individual commodity futures to examine the predictability of the chosen instruments (e.g., Bessembinder and Chan, 1992, Bjornson and Carter, 1997) or passive commodity indices (e.g., Bakshi et al., 2011, Hong and Yogo, 2012). We consider dynamic portfolio strategies via commodity indices rather than individual commodity futures which represent passive strategies. Interestingly, Gargano and Timmerman (2014) who examine the predictability of (spot) commodity indices also provide weak evidence that returns on commodity indices can be predicted by a set of macroeconomic variables over the period 1947-2010.

\section{Conclusions}

One of the key yet still open questions is whether commodities offer diversification benefits once included in a portfolio that consists of traditional asset classes. The previous literature does not reach a unanimous agreement. Most importantly, to answer this question, it makes strong assumptions on investor's preferences and on the distributional properties of asset returns. We revisit this research question and we bypass these two obstacles by employing the non-parametric stochastic dominance efficiency (SDE) setting which accommodates any utility function to the extent that the investor is greedy or greedy and risk averse as well as any distribution for asset returns. To the best of our knowledge, the application of the SDE setting for the purposes of investigating the diversification benefits of commodities is novel. 
We conduct our analysis both in- and out-of-sample by constructing and comparing optimal portfolios derived from two respective asset universes: one that includes only the traditional asset classes (equities, bonds and cash) and one that is augmented with commodities, too. To this end, we apply a two-step procedure that uses Scaillet and Topaloglou (2010) SDE test. We consider first and second order SDE criteria and we provide evidence on the performance of various first, second and third generation commodity indices in a portfolio setting.

We find that commodities provide diversification benefits. The results are robust both in- and out-of-sample for both SDE criteria, for a number of portfolio performance evaluation measures, stock indices and alternative periods. Interestingly, the evidence for diversification benefits is more pronounced in the case where the investor access commodities via second and third generation commodity indices. We explain the reported diversification benefits by documenting that commodity markets are segmented from equity and bond markets.

Our results have two implications. First, an investor should include commodities in her portfolio because commodity and traditional markets are segmented. Second, the investor should access commodities via dynamic commodity futures trading strategies such as the ones mimicked by the second and third generation indices. It would be worth exploring further the effect of transaction costs on the optimal portfolios’ performance. Most commodity indices started trading in early 2000s. This implies that trading these indices via Index Funds or Exchange Traded Funds was not possible prior to these dates and hence a replication of the index would be required. Thus, the cost of a replication strategy should be estimated using the actual weights and the actual transaction costs of the individual commodity futures contracts. It would also be worth exploring the diversification benefits of other alternative asset classes such as hedge funds by employing the SDE setting. These topics fall beyond the scope of the current study, yet they deserve to be topics for future research. 


\section{Appendix A: Mathematical formulations of Scaillet and Topaloglou (2010) test}

In this section we present the mathematical formulation of the Scaillet and Topaloglou (2010) stochastic dominance efficiency (SDE) test under the first two SDE criteria and some details on its numerical implementation for the purposes of portfolio construction.

\section{A.1 Mathematical formulation for FSDE}

To test for first order stochastic dominance efficiency (FSDE), we optimize the test statistic

$$
\hat{S}_{1}:=\sqrt{T} \sup _{z, \lambda}\left[J_{1}(z, \tau ; \hat{F})-J_{1}(z, \lambda ; \hat{F})\right]
$$

The above formulation permits testing the dominance of a given portfolio strategy $\tau$ over any potential linear combination $\lambda$ of the set of the available assets. Hence, we implement a test of stochastic dominance efficiency and not a test of standard stochastic dominance. To formulate the mathematical model of the above optimization, we will use two auxiliary binary variables to express the $J_{1}(z, \tau ; \hat{F})$ and $J_{1}(z, \lambda ; \hat{F})$ cumulative distribution functions. These are step functions in our discrete case. The mathematical formulation of the problem is the following:

$$
\begin{aligned}
& \max _{z, \lambda} S_{1}=\sqrt{T} \frac{1}{T} \sum_{t=1}^{T}\left[L_{t}-Q_{t}\right] \\
& \text { s.t. } \\
& M\left(L_{t}-1\right) \leq z-\tau^{\prime} Y_{t} \leq M L_{t}, \forall t \\
& M\left(Q_{t}-1\right) \leq z-\lambda^{\prime} Y_{t} \leq M Q_{t}, \forall t \\
& e^{\prime} \lambda=1 \\
& Q_{t} \in\{0,1\}, L_{t} \in\{0,1\}, \forall t
\end{aligned}
$$

where $M$ is the greatest portfolio return. The model is a mixed integer program maximizing the distance between the sum of two binary variables, $\frac{1}{T} \sum_{t=1}^{T} L_{t}, \frac{1}{T} \sum_{t=1}^{T} Q_{t}$, which represent $J_{1}(z, \tau ; \hat{F})$ and $J_{1}(z, \lambda ; \hat{F})$, respectively; sums are taken over all possible values of portfolio returns. We need to constrain the 
binary variable $L_{t}$ to be equal to 1 if $\mathrm{z} \geq \tau^{\prime} \mathrm{Y}_{\mathrm{t}}$ and zero otherwise. This is achieved by using the first group of inequalities. If $\mathrm{z} \geq \tau^{\prime} Y_{t}$ these inequalities force $L_{t}$ to equal 1 , and 0 otherwise. Similarly, we need to constrain the binary variable $Q_{t}$ to be equal to 1 if $z \geq \lambda^{\prime} Y_{t}$ and zero otherwise. This is achieved using the second group of inequalities. Q $Q_{t}$ equals 1 for each return $t$ for which $\mathrm{z} \geq \lambda^{\prime} \mathrm{Y}_{\mathrm{t}}$. These two groups of inequalities ensure that the two binary variables are cumulative distribution functions. The third equation defines the sum of all weights to be unity.

To solve the problem described by equation(17), we discretize the variable $z$ and we solve smaller problems $P(r)$ in which $z$ is fixed to a given return $r$ (see Scaillet and Topaloglou 2010 for the proof). Then, we take the value for $z$ that yields the maximum distance in equation (5). The advantage of doing so is that the optimal values of the $L_{t}$ variables are known in $P(r)$ because $L_{t}$ is not a function of the (unknown) optimal portfolio weights. Hence, problem $P(r)$ boils down to the following minimization problem.

$$
\begin{aligned}
& \min _{\lambda} \sum_{t=1}^{T} Q_{t} \\
& \text { s.t. } \\
& M\left(Q_{t}-1\right) \leq r-\lambda^{\prime} Y_{t} \leq M Q_{t} \\
& e^{\prime} \lambda=1, \\
& Q_{t} \in\{0,1\}, \forall t
\end{aligned}
$$

In this case, we only have one auxiliary binary variable, $Q_{t}$, so the problem is solved much faster.

\section{A.2 Mathematical formulation for SSDE}

The model for second order stochastic dominance efficiency is formulated in terms of standard linear programming. Numerical implementation of first order stochastic dominance efficiency is much more computationally demanding because we need to develop mixed integer programming formulations. To 
test for second order stochastic dominance efficiency (SSDE) of portfolio $\tau$ over any potential linear combination $\lambda$, we optimize the test statistic

$$
\hat{S}_{2}:=\sqrt{T} \sup _{z, \lambda}\left[J_{2}(z, \tau ; \hat{F})-J_{2}(z, \lambda ; \hat{F})\right]
$$

The mathematical formulation of the problem is the following

$$
\begin{aligned}
& \max _{z, \lambda} S_{2}=\sqrt{T} \frac{1}{T} \sum_{t=1}^{T}\left[L_{t}-W_{t}\right] \\
& \text { s.t. } \\
& M\left(F_{t}-1\right) \leq z-\tau^{\prime} Y_{t} \leq M F_{t} \\
& -M\left(1-F_{t}\right) \leq L_{t}-\left(z-\tau^{\prime} Y_{t}\right) \leq M\left(1-F_{t}\right) \\
& -M F_{t} \leq L_{t} \leq M F_{t} \\
& W_{t} \geq z-\lambda^{\prime} Y_{t} \\
& e^{\prime} \lambda=1 \\
& W_{t} \geq 0, F_{t} \in\{0,1\}, \forall t
\end{aligned}
$$

The model is a mixed integer program maximizing the distance between the sum of all returns over $t$ of two variables, $\frac{1}{T} \sum_{t=1}^{T} L_{t}-\frac{1}{T} \sum_{t=1}^{T} W_{t}$ for each given value of $z$, which represent $J_{2}(z, \tau ; \hat{F}), J_{2}(z, \lambda ; \hat{F})$, respectively. Again, we will use one auxiliary binary variable $F_{t}$. According to the first group of inequalities, $F_{t}$ equals 1 for each return $t$ for which $\mathrm{z} \geq \tau^{\prime} Y_{t}$, and 0 otherwise. Analogously, the second and third groups of inequalities ensure that the variable $L_{t}$ equals $z-\tau^{\prime} Y_{t}$ for the scenarios for which the difference is positive, and 0 otherwise. The fourth and last inequalities ensure that $\mathrm{W}_{t}$ equals $\mathrm{z}-\lambda^{\prime} \mathrm{Y}_{\mathrm{t}}$ for the scenarios for which the difference is positive, and 0 otherwise. The fifth equation defines the sum of all weights to be unity.

For computational convenience, we reformulate the problem, following the same steps as for first-order stochastic dominance efficiency. Then, the model is transformed to the following linear program 


$$
\begin{aligned}
& \min _{\lambda} \sum_{t=1}^{T} W_{t} \\
& \text { s.t. } \\
& W_{t} \geq r-\lambda^{\prime} Y_{t}, \forall t \\
& e^{\prime} \lambda=1, \\
& W_{t} \geq 0, \forall t
\end{aligned}
$$

\section{A.3 Portfolio construction and numerical implementation}

From a computational time cost perspective, it takes one hour to solve the FSDE model described in Section A.1. This is a considerable amount of time given that to solve the model we discretize $z$ and we solve the FSDE problem for each discrete value of $z$. We have 120 different $z$ since we have 120 observations at each point in time (rolling window of 120 observations). Hence, we solve 120 mixed integer programming problems for each commodity index for each one of the 165 out-of-sample points in time. In contrast, the solution of the SSDE problem described in Section A.2 is not computationally expensive since it takes less than one minute to solve it at each point in time. We solve the FSDE and SSDE problems with Gurobi solver on an iMac with 4*2.93 GHz Power, 16 GB of RAM. The Gurobi solver uses the branch and bound technique. We model the optimization problems by using GAMS (General Algebraic Modeling System). 


\section{Appendix B: Description of the commodity indices}

\section{First generation commodity indices}

S\&P GSCI was launched in January 1991 with historical data available since January 1970. The index currently invests in twenty four commodities classified into five groups (energy, precious metals, industrial metals, agricultural and livestock) and is heavily concentrated on the energy sector (almost $70 \%$ of the total index value). The S\&P GSCI is a world-production weighted index based on the average quantity of production of each commodity in the index over the last five years of available data. DJ-UBSCI was launched in July 1998 with historical data beginning on January 1991. The index invests in nineteen commodities from the energy, precious metals, industrial metals, agricultural and livestock sectors. In contrast to the S\&P GSCI, the DJ-UBSCI relies on two important rules to ensure diversification: the minimum and maximum allowable weight for any single commodity is $2 \%$ and $15 \%$, respectively, and the maximum allowable weight for any sector is 33\%. The DJ-UBSCI construction algorithm constructs weights by taking liquidity and (to a smaller extent) production into account. DBLCI was launched in 2003 with available price history since 1 December 1988 . It tracks the performance of six commodities in the energy, precious metals, industrial metals and grain sectors. The chosen commodity futures contracts represent the most liquid contracts in their respective sectors. DBLCI has a constant weights scheme which reflects world production and inventory, thus providing a diverse and balanced commodity exposure (for a detailed description of the first generation indices, see also for instance, Geman, 2005, Erb and Harvey, 2006).

\section{Second generation commodity indices}

JPMCCI was launched in November 2007 with historical data available since December 1989. JPMCCI includes thirty three commodities and it uses commodity futures open interest to determine the inclusion 
and relative weights of the individual commodity futures. DBLCI-OY was launched in May 2006 with historical data available since December 1988. The index components and weighting scheme are identical with these of DBLCI. DBLCI-OY is designed to select the futures contracts that either maximises the positive roll yield in backwardated term structures or minimises the negative roll yield in contangoed markets from the list of tradable futures that expire in the next 13 months. The Morningstar Commodity indices were launched in 2007 with historical data beginning on 1980.

To be considered for inclusion in the Morningstar Commodity Index family, a commodity should have futures contracts traded in one of the U.S. exchanges and being ranked in the top $95 \%$ by the 12 month average of total dollar value of open interest. Morningstar indices are built based on a momentum strategy. The weight of each individual commodity index in each of the composite indices is the product of two factors: magnitude and the direction of the momentum signal. In brief, for each commodity, they calculate a "linked" price series that converts the price of the contract in effect at each point in time to a value that accounts for contract rolls. The Morningstar Long-Only index (MSDIL) is a fully collateralized commodity futures index that is long all twenty eligible commodities. The Morningstar Long-Flat index (MSDILF) is a fully collateralized commodity futures index that is long the commodities whose linked price exceeds its 12-month moving average. If the linked price is lower than its 12-month moving average, the weight of that commodity is moved into cash, i.e. it is zeroed (flat position). The Morningstar second generation indices were launched in January 2007 with historical data backfilled since December 1979.

\section{Third generation commodity indices}

Morningstar Long/Short index is a fully collateralized commodity futures index that uses the momentum rule to determine if each commodity is held long, short, or flat. At each point in time, if the linked price 
exceeds its 12-month moving average, it takes the long side in the subsequent month. Conversely, if the linked price is below its 12-month moving average, it takes the short side. An exception is made for commodities in the energy sector. If the signal for a commodity in the energy sector translates to taking a short position, the weight of that commodity is moved into cash. The Morningstar Short/Flat commodity index is a fully collateralized commodity futures index that is derived from the positions of the Long/Short index. It takes the same short positions as the Long/Short index and replaces the long positions with flat positions. The Morningstar Short-Only commodity index is a fully collateralized commodity futures index that is short in all eligible commodities. The Morningstar third generation indices were launched in January 2007 with historical data available backfilled December 1979. 


\section{References}

Abanomey, W.S., Mathur, I., 1999. The hedging benefits of commodity futures in international portfolio construction. Journal of Alternative Investments 2, 51-62.

Ankrim, E.M., Hensel, C.R., 1993. Commodities in asset allocation: A real-asset alternative to real estate? Financial Analysts Journal 49, 20-29.

Anson, M., 1999. Maximizing utility with commodity futures diversification. Journal of Portfolio Management 25, 86-94.

Asness, C.S., Moskowitz, T., Pedersen, L.H., 2013. Value and momentum everywhere. Journal of Finance 68, 929-985.

Bakshi, G., Panayotov, G., Skoulakis, G., 2011. The Baltic Dry Index as a predictor of global stock returns, commodity returns, and global economic activity. In AFA 2012 Chicago Meetings Paper.

Bakshi, G., Gao, X., Rossi, A., 2015. Understanding the Sources of Risk Underlying the Cross-Section of Commodity Returns. Working paper, University of Maryland.

Bawa, V. 1975. Optimal rules for ordering uncertain prospects. Journal of Financial Economics 2, 95121.

Bekaert, G., Urias, M.S., 1996. Diversification, integration and emerging market closed-end funds. Journal of Finance 51, 835-869.

Belousova, J., Dorfleitner, G., 2012. On the diversification benefits of commodities from the perspective of euro investors. Journal of Banking and Finance 36, 2455-2472.

Bessembinder, H. , 1992. Systematic risk, hedging pressure, and risk premiums in futures markets. Review of Financial Studies 5, 637-667.

Bessembinder, H., Chan, K., 1992. Time-varying risk premia and forecastable returns in futures markets. Journal of Financial Economics 32, 169-193. 
Boons, M., De Roon, F., Szymanowska, M. 2014. The price of commodity risk in stock and futures markets, Working paper,

Bjornson, B., Carter, C. A., 1997. New evidence on agricultural commodity return performance under time-varying risk. American Journal of Agricultural Economics 79, 918-930.

Bodie, Z., Rosansky, V.I., 1980. Risk and return in commodity futures. Financial Analysts Journal 36, 27-39.

Büyükşahin, B., Robe, M.A. 2014. Speculators, commodities and cross-market linkages. Journal of International Money and Finance 42, 38-70.

Campbell, J. Y., Hamao, Y., 1992. Predictable stock returns in the United States and Japan: A study of long-term capital market integration. Journal of Finance 47, 43-69.

Cao, B., Jayasuriya, S., Shambora, W., 2010. Holding a commodity futures index fund in a globally diversified portfolio: A placebo effect? Economics Bulletin 30, 1842-1851.

Chan, K. F., Treepongkaruna, S., Brooks, R., Gray, S. 2011. Asset market linkages: Evidence from financial, commodity and real estate assets. Journal of Banking and Finance 35, 1415-1426.

Chen, S. S., 2007. Does monetary policy have asymmetric effects on stock returns? Journal of Money, Credit and Banking 39, 667-688.

CME Group, 2016, The Big Picture: A Cost Comparison of Futures and ETFs, 2nd Edition.

Croft, H., Norrish, K., 2013. The Commodity refiner: From an age of shortage to an era of enough. Barclays Commodities Research Report April.

Dai, R., 2009. Commodities in dynamic asset allocation: Implications of mean reverting commodity prices. Working paper, Tilburg University.

Daskalaki, C., Skiadopoulos G., 2011. Should investors include commodities in their portfolios after all? New evidence. Journal of Banking and Finance 25, 2606-2626. 
Daskalaki, C., Kostakis, A., Skiadopoulos, G., 2014. Are there common factors in individual commodity futures returns? Journal of Banking and Finance 40, 346-363.

Delatte, A. L., Lopez, C., 2013. Commodity and equity markets: Some stylized facts from a copula approach. Journal of Banking and Finance 37, 5346-5356.

DeMiguel, V., Garlappi, L., Uppal, R., 2009. Optimal versus naive diversification: How inefficient is the 1/N portfolio strategy? Review of Financial Studies 22, 1915-1953.

DeRoon, F. A., Nijman, T. E., Veld, C., 2000. Hedging pressure effects in futures markets. Journal of Finance 55, 1437-1456.

DeRoon, F.A., Nijman, T.E., Werker, B.J.M., 2003. Currency hedging for international stock portfolios: The usefulness of mean-variance analysis. Journal of Banking and Finance 27, 327-349.

Erb, C.B., Harvey, C.R., 2006. The strategic and tactical value of commodity futures. Financial Analysts Journal 62, 69-97.

Fama, E. F., French, K. R., 1989. Business conditions and expected returns on stocks and bonds. Journal of Financial Economics 25, 23-49

Fama, E. F., 1990. Stock returns, expected returns, and real activity. Journal of Finance 45, 1089-1108.

Fama, E. F., and French, K. R., 1993. Common risk factors in the returns on stocks and bonds. Journal of Financial Economics 33, 3-56.

Ferson, W. E., Harvey, C. R., 1991. The variation of economic risk premiums. Journal of Political Economy 99, 385-415.

Ferson, W.E., Foerster, S.R., Keim, D.B., 1993. General Tests of latent variable models and mean-variance spanning. Journal of Finance 48, 131-156.

Fishburn, P.C., 1964. Decision and value theory. Wiley, New York.

Follmer, H., Schied, A. 2011. Stochastic finance. An introduction in discrete time. De Gruyter, 3rd ed. 
Fortenbery, T.R., Hauser, R.J., 1990. Investment potential of agricultural futures contracts. American Journal of Agricultural Economics 72, 721-726.

Gargano, A., Timmermann, A., 2014. Forecasting commodity price indexes using macroeconomic and financial predictors. International Journal of Forecasting 30, 825-843.

Geman, H., 2005. Commodities and commodity derivatives: Modeling and pricing for agriculturals, metals and energy. John Wiley \& Sons Ltd, Chichester.

Giamouridis, D, Sakkas, A., Tessaromatis, N., 2014. The role of commodities in strategic asset allocation, Working paper, Athens University of Economics and Business.

Giampietro, M., Guidolin, M., Pedio, M., 2016. Can no-arbitrage SDF models with regime shifts explain the correlations between commodity, stock, and bond returns?. Working paper BAFFI CAREFIN Centre, Bocconi University.

Gorton, G.B., Rouwenhorst, G.K., 2006. Facts and fantasies about commodity futures. Financial Analysts Journal 62, 47-68.

Gorton, G.B., Hayashi, F., Rouwenhorst, K.G., 2012. The fundamentals of commodity futures returns. Review of Finance 17, 35-105.

Hadar, J., Russell, W.R., 1969. Rules for ordering uncertain prospects. American Economic Review 59, 25-34.

Hall, P., Horowitz, J. L., Jing, B.-Y., 1995. On blocking rules for the bootstrap with dependent data. Biometrika 82, 561-574.

Hanoch, G., Levy, H., 1969. The efficiency analysis of choices involving risk. Review of Economic Studies 36, 335-346.

Hodder, J.E., Jackwerth, J.C., Kolokolova, O., 2015. Improved portfolio choice using second-order stochastic dominance. Review of Finance 19, 1623-1647. 
Hong, H., Yogo, M., 2012. What does futures market interest tell us about the macroeconomy and asset prices? Journal of Financial Economics 105, 473-490.

Jensen, G.R., Johnson, R.R., Mercer, J.M., 2000. Efficient use of commodity futures in diversified portfolios. Journal of Futures Markets 20, 489-506.

Kat, H.M., Oomen, R.C., 2007. What every investor should know about commodities Part I: Univariate return analysis. Journal of Investment Management 5, 4-28.

Kostakis, A., Panigirtzoglou, N., Skiadopoulos, G., 2011. Market timing with option-implied distributions: A forward-looking approach. Management Science 57, 1231-1249.

Kuosmanen, T., 2004. Efficient diversification according to stochastic dominance criteria. Management Science 50, 1390-1406.

Levy, H., Hanoch, G., 1970. Relative effectiveness of efficiency criteria for portfolio selection. Journal of Financial and Quantitative Analysis 5, 63-76.

Levy, H., 1992, Stochastic dominance and expected utility: Survey and Analysis. Management Science 38, 555-593.

Maccheroni, F., Marinacci, M., Rustichini, A. (2006). Ambiguity aversion, robustness, and the variational representation of preferences. Econometrica 74, 1447-1498.

Markowitz, H., 1952. Portfolio selection. Journal of Finance 7, 77-91.

Memmel, C., 2003. Performance hypothesis testing with the Sharpe ratio. Finance Letters 1, 21-23.

Meyer, T. O., Li, X., Rose L. C., 2005. Comparing mean variance tests with stochastic dominance tests. Financial Services Review 14, 149-168.

Miffre, J., 2012. Comparing first, second and third generation commodity indices, Working paper, EDHEC Business School.

Mou, Y., 2011. Limits to arbitrage and commodity index investment: Front-running the Goldman roll, Working paper, Columbia University. 
Post, T., 2003. Empirical tests for stochastic dominance efficiency. Journal of Finance 58, 1905-1031.

Post T, Versijp, P. 2007. Multivariate tests for stochastic dominance efficiency of a given portfolio. Journal of Financial and Quantitative Analysis 42, 489-515.

Post, T., Kopa, M., 2013. General linear formulations of stochastic dominance criteria. European Journal of Operational Research 230, 321-332.

Quirk, J.P., Saposnik R., 1962. Admissibility and Measurable Utility Function. Review of Economic Studies, 29, 140-146.

Rallis, G., Miffre, J., Fuertes, A. M., 2013. Strategic and tactical roles of enhanced commodity indices. Journal of Futures Markets, 33, 965-992.

Rothschild, M., Stiglitz, J.E., 1970. Increasing risk I: A definition. Journal of Economic Theory 2, 225243.

Scaillet, O., Topaloglou, N., 2010. Testing for stochastic dominance efficiency, Journal of Business and Economic Statistics 28, 169-180.

Silvennoinen, A., Thorp, S., 2013. Financialization, crisis and commodity correlation dynamics. Journal of International Financial Markets, Institutions and Money 24, 42-65.

Simaan, Y., 1993. What is the opportunity cost of mean-variance investment strategies? Management Science 39, 578-587.

Skiadopoulos, G., 2013. Advances in the commodity futures literature: A review. Journal of Derivatives 20, 85-96.

Szakmary, A.C., Shen, Q., Sharma, S.C., 2010. Trend-following trading strategies in commodity futures: A re-examination. Journal of Banking \& Finance 34, 409-426.

Tang, K., Xiong, W., 2012. Index investing and the financialization of commodities. Financial Analysts Journal 68, 54-74. 
Figure 1. First-degree stochastic dominance efficiency of portfolio $\lambda$ over the market portfolio $\tau$.

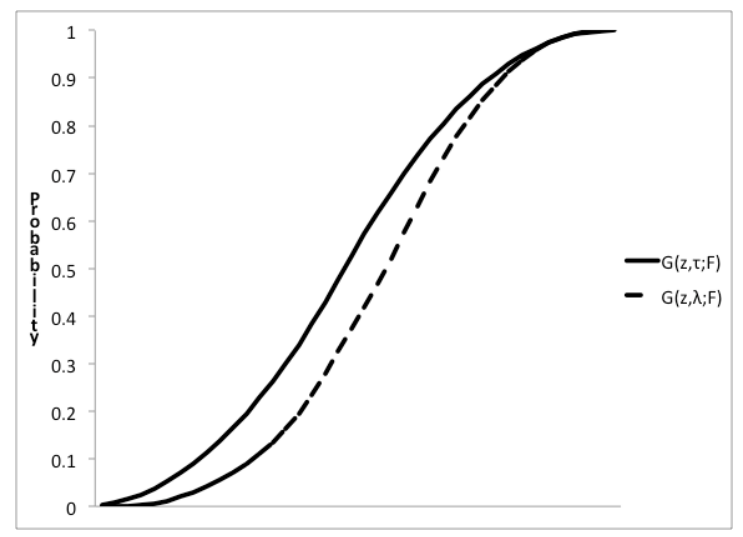

Figure 2. Second-degree stochastic dominance efficiency of portfolio $\lambda$ over the market portfolio $\tau$.

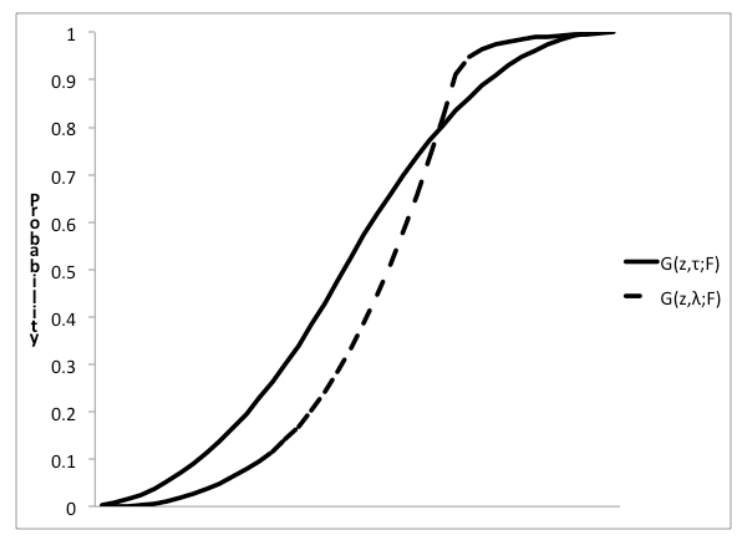


Table 1: Description of the Indices

Entries describe the set of stock, bond and commodity indices employed in this study.

\section{First Generation Indices
Deutshe Bank Liquid Commodity Index (DBLCI)}

S\&P Goldman Sachs Commodity Index (S\&P GSCI)

Dow-Jones-UBS Commodity Index (DJ UBS CI)

Second Generation Indices

JP Morgan Commodity Curve Index (JPMCCI)

DBLCI-Optimum Yield (DBLCI-OY)

Morningstar Long-Only Commodity Index (MSDIL)

Morningstar Long/Flat Commodity Index (MSDILF)

\section{Third Generation Indices}

Morningstar Short-Only Commodity Index (MSDIS)

Morningstar Long/Short Commodity Index (MSDILS)

Morningstar Short/Flat Commodity Index (MSDISF)

\section{Equity Indexes}

S\&P 500 Total Return

Small minus Big Factor (SMB)

High minus Low Factor (HML)

Bond Index

Barclays US Aggregate Bond Index
Constituents

Strategy

6 commodities from the energy, precious metals, industrial metals and grain The relative weight of each commodity remains constrant and is determined by world production and inventory data.

24 commodities from the energy, precious metals, industrial metals, agricultural The relative weight of each commodity is determined by world production data over the last five years. The index is and livestock sectors.
heavily concentrated on the energy sector (about $70 \%$ ).

19 commodities from the energy, precious metals, industrial metals, agricultural The relative weight of each commodity is determined primarily by liquidity data, and to a smaller extent by production. and livestock sectors.

The index relies on two rules: the minimum and the maximum allowable weight for any single commodity is $2 \%$ and $15 \%$, respectively, and the maximum allowable for any sector is $33 \%$.

33 commodities from the energy, precious metals, industrial metals, agricultural The relative weight of each commodity is determined by its open interest. The index adopts a simple, curve-neutral and livestock sectors.

6 commodities, the same as DBLCI. approach, holding exposure along the commodity futures curve according to the open interest of each tenor.

The relative weight of each commodity is identical with DBLCI. The index is designed to select the futures contracts that either maximises the positive roll yield in backwardated term structures or minimises the negative roll yield in 20 most liquid commodity futures contracts, traded in U.S. exchanges and contangoed markets from the list of tradeable futures that expire in the next 13 month.

ranked in the top $95 \%$ by the 12 -month average of total dollar value of open The index is long all eligible commodities.

interest.

20 most liquid commodity futures contracts, traded in U.S. exchanges and The relative weight of each commodity is the product of two factors: magnitude and the direction of the momentum ranked in the top $95 \%$ by the 12 -month average of total dollar value of open signal. The index is long the commodities whose product exceeds its 12 -month moving average. If it is lower than its interest. 12 -month moving average, the weight of that commodity is moved into cash (flat position).

20 most liquid commodity futures contracts, traded in U.S. exchanges and

ranked in the top $95 \%$ by the 12-month average of total dollar value of open The index is short all eligible commodities.

interest.

20 most liquid commodity futures contracts, traded in U.S. exchanges and The relative weight of each commodity is the product of two factors: magnitude and the direction of the momentum ranked in the top $95 \%$ by the 12-month average of total dollar value of open signal. If this product exceeds its 12 -month moving average, it takes the long side in the subsequent month. If it is interest. below its 12-month moving average, it takes the short side.

20 most liquid commodity futures contracts, traded in U.S. exchanges and The relative weight of each commodity is the product of two factors: magnitude and the direction of the momentum ranked in the top $95 \%$ by the 12-month average of total dollar value of open signal If the product is below its 12-month moving average, the index takes the short side. If it exceeds its 12 -month interest. average, the weight of that commodity is moved into cash (flat position).

500 large companies having common stock listed on the NYSE or NASDAQ.

The index has traditionally been capitalization-weighted. that is, movements in the prices of stocks with higher market than do companies with smaller market caps. - value

6 value-weighted portfolios of stocks listed on the NYSE, AMEX, or The difference in the return of a portfolio of small capitalization stocks and the return of a portfolio of large NASDAQ formed based on market capitalization. capitalization stocks.

6 value-weighted portfolios of stocks listed on the NYSE, AMEX, or The difference between the return of a portfolio of high book-to-market stocks and the return of a portfolio of low NASDAQ formed based on book-to-market figures. book-to-market stocks.

Most U.S. traded investment grade bonds are represented. It is a long-term

index that includes Treasury securities, Government agency bonds, Mortgage- It is a market capitalization-weighted index, meaning the securities in the index are weighted according to the market backed bonds, Corporate bonds, and a small amount of foreign bonds traded in size of each bond type. 
Table 2: Descriptive Statistics

Entries report the descriptive statistics for the alternative asset classes used in this study. The annualized mean returns (with the respective $t$-statistics), the standard deviations, the Sharpe Ratios as well as the skewness and the kurtosis figures are reported. The dataset spans January 1990 to September 2013, with the exception of DJ-UBSCI that covers January 1991 to September 2013.

\begin{tabular}{|c|c|c|c|c|c|c|}
\hline & $\begin{array}{c}\text { Annualized } \\
\text { Average Return }\end{array}$ & tstat & $\begin{array}{c}\text { Annualized } \\
\text { Standard } \\
\text { Deviation }\end{array}$ & $\begin{array}{c}\text { Annualized } \\
\text { Sharpe Ratio }\end{array}$ & Skewness & Kurtosis \\
\hline \multicolumn{7}{|l|}{ First Generation indices } \\
\hline Deutsche Bank Liquid Commodity Index & 0.097 & $(2.265)$ & 0.208 & 0.292 & 0.208 & 5.644 \\
\hline S\&P Goldman Sachs Commodity Index & 0.063 & $(1.426)$ & 0.213 & 0.124 & -0.148 & 5.078 \\
\hline Dow-Jones-UBS Commodity Index & 0.055 & $(1.777)$ & 0.149 & 0.142 & -0.562 & 5.666 \\
\hline \multicolumn{7}{|l|}{ Second Generation indices } \\
\hline JP Morgan Commodity Curve Index & 0.078 & $(2.421)$ & 0.157 & 0.265 & -0.575 & 5.985 \\
\hline DBLCI-Optimum Yield & 0.104 & $(2.876)$ & 0.175 & 0.385 & -0.190 & 5.455 \\
\hline Morningstar Long/Flat Commodity Index & 0.087 & $(4.026)$ & 0.105 & 0.482 & 0.117 & 5.654 \\
\hline Morningstar Long-Only Commodity Index & 0.087 & $(2.712)$ & 0.157 & 0.325 & -0.361 & 5.607 \\
\hline \multicolumn{7}{|l|}{ Third Generation Indices } \\
\hline Morningstar Short/Flat Commodity Index & 0.039 & (3.325) & 0.057 & 0.049 & 0.573 & 7.204 \\
\hline Morningstar Long/Short Commodity Index & 0.093 & (4.193) & 0.107 & 0.529 & 0.225 & 4.992 \\
\hline Morningstar Short-Only Commodity Index & -0.007 & $(-0.248)$ & 0.149 & -0.293 & 0.499 & 5.558 \\
\hline \multicolumn{7}{|l|}{ Equity Indices } \\
\hline S\&P 500 Total Return & 0.099 & $(3.228)$ & 0.149 & 0.419 & -0.601 & 4.137 \\
\hline SMB & 0.026 & $(1.108)$ & 0.115 & -0.088 & 0.823 & 11.382 \\
\hline HML & 0.048 & $(2.146)$ & 0.109 & 0.111 & 0.619 & 5.755 \\
\hline \multicolumn{7}{|l|}{ Bond Index } \\
\hline Barclays US Aggregate Bond Index & 0.065 & $(8.455)$ & 0.037 & 0.769 & -0.270 & 3.739 \\
\hline
\end{tabular}


Table 3: In-sample testing for Stochastic Dominance Efficiency: Jan. 1990 - Sep. 2013

Entries report the Scaillet and Topaloglou (2010) FSDE and SSDE test statistics and respective $p$-values (within parentheses) for the null hypothesis that a set of benchmark assets consisting of stocks, bonds and the risk-free asset are SD efficient versus the benchmark assets plus the commodity asset. We access investment in commodities via first, second and third generation indices, separately. Panel A reports the results when the benchmark set of assets consists of the S\&P 500 Total Return Index, Barclays Aggregate Bond Index and 1-month LIBOR. Panels B and C report the results when the benchmark set includes dynamic equity indices, i.e. the Fama-French (1993) size factor (Small minus Big, SMB) and the value factor (High minus Low, HML), respectively. Results are based on monthly observations from Jan. 1990 -Sep. 2013. One and two asterisks indicate that the null hypothesis of spanning can be rejected at $10 \%$ and $5 \%$ significance level, respectively.

Test Asset

Panel A: S\&P 500

Panel B: SMB

Panel C:HML

First generation indices

Deutsche Bank Liquid Commodity Index

FSI

SSD

FSD

SSD

FSD

SSD

$0.087 * *$

(0.049)

$0.005 *$

$0.049 *$

$0.087 *$

(0.053)

(0.068)

$0.048 *$

$0.004 *$

(0.093)

$0.006 * *$

(0.098)

0.088

(0.055)

$0.088 * *$

$0.047 * *$

Dow-Jones-UBS Commodity Index

(0.044)

$0.005 *$

(0.104)

0.019

(0.115)

$0.087^{*}$

$0.048 *$

(0.037)

(0.014)

$0.087 *$

$0.019 *$

(0.087)

(0.085)

Second generation indices

JP Morgan Commodity Curve Index

0.087

(0.051)

(0.053)

(0.052)

$0.060 * *$

$0.048 * *$

(0.065)

$0.087 *$

$0.0031^{*}$

$0.087 * *$

$0.029 *$

(0.039)

(0.041)

Deutsche Bank Liquid Commodity Index-Optimum Yield

(0.083)

Morningstar Long/Flat Commodity Index

$0.014 * *$

(0.077)

(0.048)

$0.0117^{*}$

$0.013^{*}$

(0.029)

$0.087 * *$

(0.073)

(0.063)

Morningstar Long-Only Commodity Index

(0.038)

$0.014^{* *}$

(0.056)

$0.014 *$

$0.035^{* *}$

$0.029 * *$

(0.039)

(0.044)

(0.065)

$0.011^{*}$

$0.0065^{* *}$

(0.054)

$0.017 * *$

$0.005 * *$

(0.047)

(0.045)

(0.027)

$0.044 * \quad 0.086 * *$

$0.016 *$

$0.070^{* *}$

0.044* $\quad 0.086^{* *}$

(0.065)

(0.044)

$0.018 * *$

(0.048)

$0.047^{*}$

0.070 **

$0.084^{* *}$

(0.017)

$0.016^{* *}$

$0.084^{* *}$

$0.021 * *$

(0.022)

$0.084^{* *}$

(0.014)

(0.037)

Morningstar Long/Short Commodity Index

(0.049)

$0.023 * *$

Morningstar Short-Only Commodity Index

(0.041)

(0.049)

(0.063)

$0.087^{*}$

(0.053)

0.009*

(0.075)

$0.048^{*}$

(0.066)

(0.039)

$0.071^{* *}$

(0.034)

$0.071^{* *}$

(0.044)

(0.049)

0.048**

(0.034)

$0.009 * *$

(0.039)

$0.049 *$

(0.057)

(0.051) 
Table 4: Out-of-sample testing for Stochastic Dominance: January 2001 - September 2013

Entries report the Scaillet and Topaloglou (2010) first and second order stochastic dominance (FSD, SSD, respectively) test statistics and respective $p$-values (within parentheses) for the null hypothesis that the optimal portfolio based on the traditional asset universe (stocks, bonds and cash) augmented with commodities stochastically dominates the optimal portfolio based on the traditional asset universe. Optimal portfolios' performance is evaluated out-ofsample. We access investment in commodities via the first generation indices, the second generation indices and the third generation indices, separately. Panel A reports results when the traditional asset universe consists of the S\&P 500 Total Return Index, Barclays Aggregate Bond Index and Libor 1-month. Panels B and C report results when the stock asset class in the traditional asset universe is proxied by dynamic equity indices, i.e. the Fama-French (1993) size factor (Small minus Big, SMB) and value factor (High minus Low, HML), respectively. Results are based on out-of-sample monthly portfolio returns spanning January 2001 -September 2013.

\begin{tabular}{|c|c|c|c|c|c|c|}
\hline Test Asset & Panel A & & Panel B & & Panel C & \\
\hline & FSD & SSD & FSD & SSD & FSD & SSD \\
\hline First generation indices & & & & & & \\
\hline Deutsche Bank Liquid Commodity Index & -0.005 & -0.004 & -0.008 & -0.005 & -0.010 & -0.006 \\
\hline & $(0.583)$ & $(0.530)$ & $(0.483)$ & $(0.560)$ & $(0.563)$ & $(0.573)$ \\
\hline S\&P Goldman Sachs Commodity Index & -0.004 & -0.003 & -0.007 & -0.002 & -0.005 & -0.005 \\
\hline & $(0.553)$ & $(0.490)$ & $(0.507)$ & $(0.577)$ & $(0.570)$ & $(0.627)$ \\
\hline Dow-Jones-UBS Commodity Index & -0.0019 & -0.002 & -0.006 & -0.003 & -0.006 & -0.004 \\
\hline & $(0.530)$ & $(0.557)$ & $(0.533)$ & $(0.537)$ & $(0.507)$ & $(0.573)$ \\
\hline Second generation indices & & & & & & \\
\hline JP Morgan Commodity Curve Index & -0.007 & -0.005 & -0.009 & -0.005 & -0.009 & -0.008 \\
\hline & $(0.533)$ & $(0.517)$ & $(0.560)$ & $(0.527)$ & $(0.543)$ & $(0.567)$ \\
\hline Deutsche Bank Liquid Commodity Index-Optimum Yield & -0.009 & -0.006 & -0.009 & -0.007 & -0.010 & -0.009 \\
\hline & $(0.517)$ & $(0.557)$ & $(0.543)$ & $(0.550)$ & $(0.590)$ & $(0.563)$ \\
\hline Morningstar Long/Flat Commodity Index & -0.006 & -0.004 & -0.008 & -0.005 & -0.007 & -0.006 \\
\hline & $(0.533)$ & $(0.560)$ & $(0.543)$ & $(0.603)$ & $(0.583)$ & $(0.570)$ \\
\hline Morningstar Long-Only Commodity Index & -0.009 & -0.006 & -0.009 & -0.006 & -0.008 & -0.008 \\
\hline & $(0.487)$ & $(0.487)$ & $(0.507)$ & $(0.583)$ & $(0.610)$ & $(0.567)$ \\
\hline Third generation indices & & & & & & \\
\hline Morningstar Short/Flat Commodity Index & -0.003 & 0.001 & -0.003 & -0.002 & -0.004 & -0.002 \\
\hline & $(0.527)$ & $(0.503)$ & $(0.477)$ & $(0.547)$ & $(0.550)$ & $(0.563)$ \\
\hline Morningstar Long/Short Commodity Index & -0.002 & -0.002 & -0.007 & -0.004 & -0.009 & -0.005 \\
\hline & $(0.510)$ & $(0.560)$ & $(0.510)$ & $(0.570)$ & $(0.510)$ & $(0.517)$ \\
\hline Morningstar Short-Only Commodity Index & -0.005 & -0.002 & -0.004 & -0.003 & -0.005 & -0.004 \\
\hline & $(0.513)$ & $(0.547)$ & $(0.493)$ & $(0.523)$ & $(0.547)$ & $(0.520)$ \\
\hline
\end{tabular}


Table 5: Out-of-sample performance: Parametric portfolio measures

Entries report the performance measures (annualized Sharpe Ratio, annualized Opportunity Cost, Portfolio Turnover, annualized Return-Loss) when the benchmark set includes the S\&P 500 Equity Index, the Barclays US Aggregate Bond Index and the 1-month LIBOR. The $p$-values of Memmel's (2003) test are also reported within parentheses; the null hypothesis is that the SR obtained from the traditional investment opportunity set is equal to that derived from the expanded set that includes commodities. The results for the opportunity cost are reported for different degrees of absolute risk aversion $(A R A=2,4,6)$ and different degrees of relative risk aversion (RRA=2, 4, 6). Investors access investment in commodities separately via first generation indices, second generation indices and third generation indices, separately. The dataset for all assets spans Jan. 1990-Sep. 2013 with the exception of DJ-UBSCI that spans Jan. 1991 to Sep.2013 due to data availability constraints. The out-of-sample analysis is conducted over Jan. 2001-Sep. 2013. Panels A and B report the results for the first and second order stochastic dominance efficiency, respectively.

\begin{tabular}{|c|c|c|c|c|c|c|c|c|c|c|c|}
\hline \multicolumn{12}{|c|}{ Panel A: First Order Stochastic Dominance } \\
\hline & \multicolumn{4}{|c|}{ 1st generation indices } & \multicolumn{3}{|c|}{2 nd generation indices } & \multirow[b]{2}{*}{ MSDIL } & \multicolumn{3}{|c|}{3 rd generation indices } \\
\hline & Benchmark set & S\&P GSCI & DJ-UBS CI & DBLCI & JPMCCI & $\begin{array}{l}\text { DBLCI- } \\
\text { OY }\end{array}$ & MSDILF & & MSDISF & MSDILS & MSDIS \\
\hline Sharpe Ratio & 0.21 & 0.35 & 0.34 & 0.42 & 0.74 & 0.79 & 0.77 & 0.81 & 0.60 & 0.43 & 0.90 \\
\hline Memmel p-value & & 0.341 & 0.358 & 0.253 & 0.055 & 0.037 & 0.041 & 0.040 & 0.115 & 0.273 & 0.019 \\
\hline PortfolioTurnover & $8.20 \%$ & $13.37 \%$ & $3.84 \%$ & $3.49 \%$ & $4.95 \%$ & $3.45 \%$ & $2.98 \%$ & $9.19 \%$ & $6.41 \%$ & $0.95 \%$ & $3.15 \%$ \\
\hline Return-Loss & & $0.71 \%$ & $1.40 \%$ & $1.96 \%$ & $6.16 \%$ & $6.63 \%$ & $6.98 \%$ & $6.83 \%$ & $5.23 \%$ & $2.95 \%$ & $9.38 \%$ \\
\hline \multicolumn{12}{|l|}{ Opportunity Cost } \\
\hline \multicolumn{12}{|l|}{ Exponential Utility } \\
\hline ARA $=2$ & & $1.80 \%$ & $1.68 \%$ & $3.60 \%$ & $7.92 \%$ & $9.00 \%$ & $7.08 \%$ & $9.24 \%$ & $4.08 \%$ & $2.64 \%$ & $6.48 \%$ \\
\hline $\mathrm{ARA}=4$ & & $-0.60 \%$ & $1.08 \%$ & $1.44 \%$ & $6.96 \%$ & $7.80 \%$ & $6.96 \%$ & $8.16 \%$ & $4.56 \%$ & $2.64 \%$ & $7.20 \%$ \\
\hline $\mathrm{ARA}=6$ & & $-3.24 \%$ & $0.36 \%$ & $-0.84 \%$ & $6.00 \%$ & $6.60 \%$ & $6.96 \%$ & $7.08 \%$ & $5.04 \%$ & $2.76 \%$ & $7.80 \%$ \\
\hline \multicolumn{12}{|l|}{ Power Utility } \\
\hline $\mathrm{RRA}=2$ & & $1.80 \%$ & $1.68 \%$ & $3.24 \%$ & $7.92 \%$ & $9.00 \%$ & $7.08 \%$ & $9.24 \%$ & $4.08 \%$ & $2.64 \%$ & $6.48 \%$ \\
\hline $\mathrm{RRA}=4$ & & $-0.72 \%$ & $0.96 \%$ & $1.08 \%$ & $6.96 \%$ & $7.80 \%$ & $6.96 \%$ & $8.16 \%$ & $4.56 \%$ & $2.76 \%$ & $7.20 \%$ \\
\hline RRA $=6$ & & $-3.36 \%$ & $0.24 \%$ & $-1.32 \%$ & $5.88 \%$ & $6.48 \%$ & $6.96 \%$ & $7.08 \%$ & $5.04 \%$ & $2.76 \%$ & $7.92 \%$ \\
\hline
\end{tabular}


Table 5: Out-of-sample performance: Parametric portfolio measures (cont'd)

Entries report the performance measures (annualized Sharpe Ratio, annualized Opportunity Cost, Portfolio Turnover, annualized Return-Loss) when the benchmark set includes the S\&P 500 Equity Index, the Barclays US Aggregate Bond Index and the 1-month LIBOR. The $p$-values of Memmel's (2003) test are also reported within parentheses; the null hypothesis is that the SR obtained from the traditional investment opportunity set is equal to that derived from the expanded set that includes commodities. The results for the opportunity cost are reported for different degrees of absolute risk aversion $(A R A=2,4,6)$ and different degrees of relative risk aversion (RRA=2, 4, 6). Investors access investment in commodities separately via first generation indices, second generation indices and third generation indices, separately. The dataset for all assets spans Jan. 1990-Sep. 2013 with the exception of DJ-UBSCI that spans Jan. 1991 to Sep.2013 due to data availability constraints. The out-of-sample analysis is conducted over the period from Jan. 2001-Sep. 2013. Panels A and B report the results for the first and second order stochastic dominance efficiency, respectively.

\begin{tabular}{|c|c|c|c|c|c|c|c|c|c|c|c|}
\hline \multicolumn{12}{|c|}{ Panel B: Second Order Stochastic Dominance } \\
\hline & & \multicolumn{3}{|c|}{ 1st generation indices } & \multicolumn{4}{|c|}{ 2nd generation indices } & \multicolumn{3}{|c|}{ 3rd generation indices } \\
\hline & Benchmark set & $\begin{array}{c}\text { S\&P } \\
\text { GSCI }\end{array}$ & $\begin{array}{c}\text { DJ-UBS } \\
\text { CI }\end{array}$ & DBLCI & JPMCCI & $\begin{array}{c}\text { DBLCI- } \\
\text { OY }\end{array}$ & MSDILF & MSDIL & MSDISF & MSDILS & MSDIS \\
\hline Sharpe Ratio & 0.21 & 0.36 & 0.32 & 0.39 & 0.49 & 0.53 & 0.58 & 0.58 & 0.27 & 0.43 & 0.63 \\
\hline Memmel p-value & & 0.339 & 0.376 & 0.317 & 0.224 & 0.191 & 0.161 & 0.166 & 0.437 & 0.289 & 0.132 \\
\hline PortfolioTurnover & $7.32 \%$ & $28.75 \%$ & $13.82 \%$ & $7.89 \%$ & $5.56 \%$ & $2.78 \%$ & $4.03 \%$ & $7.65 \%$ & $15.32 \%$ & $0.95 \%$ & $5.42 \%$ \\
\hline Return-Loss & & $0.40 \%$ & $0.77 \%$ & $1.19 \%$ & $2.66 \%$ & $2.99 \%$ & $4.19 \%$ & $3.54 \%$ & $2.87 \%$ & $2.67 \%$ & $5.93 \%$ \\
\hline \multicolumn{12}{|l|}{ Opportunity Cost } \\
\hline \multicolumn{12}{|l|}{ Exponential Utility } \\
\hline $\mathrm{ARA}=2$ & & $2.04 \%$ & $1.44 \%$ & $2.52 \%$ & $4.32 \%$ & $5.16 \%$ & $4.44 \%$ & $5.76 \%$ & $-0.12 \%$ & $2.64 \%$ & $3.24 \%$ \\
\hline $\mathrm{ARA}=4$ & & $0.24 \%$ & $0.60 \%$ & $-0.48 \%$ & $2.40 \%$ & $2.64 \%$ & $4.20 \%$ & $3.96 \%$ & $1.08 \%$ & $2.52 \%$ & $3.96 \%$ \\
\hline $\mathrm{ARA}=6$ & & $-1.68 \%$ & $-0.24 \%$ & $-3.72 \%$ & $0.24 \%$ & $-0.12 \%$ & $4.08 \%$ & $1.80 \%$ & $2.16 \%$ & $2.28 \%$ & $4.68 \%$ \\
\hline \multicolumn{12}{|l|}{ Power Utility } \\
\hline $\mathrm{RRA}=2$ & & $1.92 \%$ & $1.44 \%$ & $2.40 \%$ & $4.20 \%$ & $5.04 \%$ & $4.44 \%$ & $5.76 \%$ & $-0.12 \%$ & $2.64 \%$ & $3.24 \%$ \\
\hline $\mathrm{RRA}=4$ & & $0.12 \%$ & $0.60 \%$ & $-0.72 \%$ & $2.16 \%$ & $2.52 \%$ & $4.20 \%$ & $3.84 \%$ & $1.08 \%$ & $2.52 \%$ & $3.96 \%$ \\
\hline $\mathrm{RRA}=6$ & & $-1.92 \%$ & $-0.36 \%$ & $-4.32 \%$ & $-0.24 \%$ & $-0.48 \%$ & $4.08 \%$ & $1.56 \%$ & $2.16 \%$ & $2.28 \%$ & $4.68 \%$ \\
\hline
\end{tabular}




\section{Table 6: Out-of-sample performance: Parametric portfolio measures and a value strategy}

Entries report the performance measures (annualized Sharpe Ratio, annualized Opportunity Cost, Portfolio Turnover, annualized Return-Loss) when the benchmark set includes the Value Factor (HML), the Barclays US Aggregate Bond Index and the 1-month LIBOR. The $p$-values of Memmel's (2003) test are also reported within parentheses; the null hypothesis is that the SR obtained from the traditional investment opportunity set is equal to that derived from the expanded set that includes commodities. The results for the opportunity cost are reported for different degrees of absolute risk aversion $(A R A=2,4,6)$ and different degrees of relative risk aversion ( $R R A=2,4,6)$. Investors access investment in commodities separately via first generation indices, second generation indices and third generation indices, separately. The dataset for all assets spans Jan. 1990-Sep. 2013 with the exception of DJ-UBSCI that spans Jan. 1991 to Sep.2013 due to data availability constraints. The out-of-sample analysis is conducted over the period from Jan. 2001-Sep. 2013. Panels A and B report the results for the first and second order stochastic dominance efficiency, respectively.

\begin{tabular}{|c|c|c|c|c|c|c|c|c|c|c|c|}
\hline \multicolumn{12}{|c|}{ Panel A: First Order Stochastic Dominance } \\
\hline & & \multicolumn{3}{|c|}{ 1st generation indices } & \multicolumn{3}{|c|}{ 2nd generation indices } & \multicolumn{4}{|c|}{ 3rd generation indices } \\
\hline & & S\&P & DJ-UBS & & & DBLCI- & & & & & \\
\hline & Benchmark set & GSCI & CI & DBLCI & JPMCCI & OY & MSDILF & MSDIL & MSDISF & MSDILS & MSDIS \\
\hline Sharpe Ratio & 0.05 & 0.76 & 0.49 & 0.77 & 0.76 & 0.87 & 0.75 & 0.67 & 0.56 & 0.87 & 0.53 \\
\hline Memmel p-value & & 0.017 & 0.088 & 0.018 & 0.018 & 0.012 & 0.027 & 0.039 & 0.060 & 0.012 & 0.031 \\
\hline PortfolioTurnover & $3.88 \%$ & $17.48 \%$ & $10.57 \%$ & $8.34 \%$ & $16.17 \%$ & $6.73 \%$ & $8.29 \%$ & $6.71 \%$ & $14.46 \%$ & $7.54 \%$ & $11.54 \%$ \\
\hline Return-Loss & & $8.04 \%$ & $4.87 \%$ & $8.32 \%$ & $8.07 \%$ & $9.73 \%$ & $8.66 \%$ & $7.19 \%$ & $6.75 \%$ & $9.95 \%$ & $5.92 \%$ \\
\hline \multicolumn{12}{|l|}{ Opportunity Cost } \\
\hline \multicolumn{12}{|l|}{ Exponential Utility } \\
\hline $\mathrm{ARA}=2$ & & $10.32 \%$ & $6.24 \%$ & $10.92 \%$ & $10.20 \%$ & $11.88 \%$ & $8.64 \%$ & $8.88 \%$ & $5.40 \%$ & $11.04 \%$ & $5.88 \%$ \\
\hline $\mathrm{ARA}=4$ & & $9.60 \%$ & $5.52 \%$ & $9.84 \%$ & $9.60 \%$ & $11.16 \%$ & $8.76 \%$ & $8.16 \%$ & $6.12 \%$ & $10.80 \%$ & $6.12 \%$ \\
\hline $\mathrm{ARA}=6$ & & $8.88 \%$ & $4.80 \%$ & $8.76 \%$ & $8.88 \%$ & $10.56 \%$ & $9.00 \%$ & $7.44 \%$ & $6.96 \%$ & $10.56 \%$ & $6.48 \%$ \\
\hline \multicolumn{12}{|l|}{ Power Utility } \\
\hline $\mathrm{RRA}=2$ & & $10.32 \%$ & $6.24 \%$ & $11.04 \%$ & $10.20 \%$ & $11.88 \%$ & $8.64 \%$ & $8.88 \%$ & $5.40 \%$ & $11.04 \%$ & $5.88 \%$ \\
\hline $\mathrm{RRA}=4$ & & $9.60 \%$ & $5.52 \%$ & $9.84 \%$ & $9.60 \%$ & $11.16 \%$ & $8.76 \%$ & $8.16 \%$ & $6.24 \%$ & $10.80 \%$ & $6.12 \%$ \\
\hline $\mathrm{RRA}=6$ & & $8.88 \%$ & $4.68 \%$ & $8.76 \%$ & $8.88 \%$ & $10.56 \%$ & $9.00 \%$ & $7.44 \%$ & $6.96 \%$ & $10.56 \%$ & $6.48 \%$ \\
\hline
\end{tabular}


Table 6: Out-of-sample performance: Parametric portfolio measures and a value strategy (cont’d)

Entries report the performance measures (annualized Sharpe Ratio, annualized Opportunity Cost, Portfolio Turnover, annualized Return-Loss) when the benchmark set includes the Value Factor (HML), the Barclays US Aggregate Bond Index and the 1-month LIBOR. The $p$-values of Memmel's (2003) test are also reported within parentheses; the null hypothesis is that the SR obtained from the traditional investment opportunity set is equal to that derived from the expanded set that includes commodities. The results for the opportunity cost are reported for different degrees of absolute risk aversion $(A R A=2,4,6)$ and different degrees of relative risk aversion $(\mathrm{RRA}=2,4,6)$. Investors access investment in commodities separately via first generation indices, second generation indices and third generation indices, separately. The dataset for all assets spans Jan. 1990-Sep. 2013 with the exception of DJ-UBSCI that spans Jan. 1991 to Sep.2013 due to data availability constraints. The out-of-sample analysis is conducted over the period from Jan. 2001-Sep. 2013. Panels A and $\mathrm{B}$ report the results for the first and second order stochastic dominance efficiency, respectively.

\begin{tabular}{|c|c|c|c|c|c|c|c|c|c|c|c|}
\hline \multicolumn{12}{|c|}{ Panel B: Second Order Stochastic Dominance } \\
\hline & \multicolumn{4}{|c|}{ 1st generation indices } & \multicolumn{4}{|c|}{ 2nd generation indices } & \multicolumn{3}{|c|}{ 3rd generation indices } \\
\hline & & S\&P & DJ-UBS & & & DBLCI- & & & & & \\
\hline & Benchmark set & GSCI & CI & DBLCI & JPMCCI & OY & MSDILF & MSDIL & MSDISF & MSDILS & MSDIS \\
\hline Sharpe Ratio & 0.04 & 0.51 & 0.42 & 0.41 & 0.65 & 0.65 & 0.62 & 0.61 & 0.42 & 0.57 & 0.56 \\
\hline Memmel p-value & & 0.094 & 0.136 & 0.153 & 0.044 & 0.050 & 0.072 & 0.059 & 0.152 & 0.094 & 0.035 \\
\hline PortfolioTurnover & $4.88 \%$ & $28.89 \%$ & $14.10 \%$ & $4.51 \%$ & $18.12 \%$ & $8.02 \%$ & $1.97 \%$ & $8.30 \%$ & $23.63 \%$ & $3.49 \%$ & $61.64 \%$ \\
\hline Return-Loss & & $4.52 \%$ & $3.96 \%$ & $3.67 \%$ & $6.36 \%$ & $6.38 \%$ & $6.89 \%$ & $6.16 \%$ & $4.80 \%$ & $6.23 \%$ & $4.39 \%$ \\
\hline \multicolumn{12}{|l|}{ Opportunity Cost } \\
\hline \multicolumn{12}{|l|}{ Exponential Utility } \\
\hline $\mathrm{ARA}=2$ & & $6.12 \%$ & $4.92 \%$ & $5.04 \%$ & $8.76 \%$ & $9.24 \%$ & $7.08 \%$ & $8.04 \%$ & $3.72 \%$ & $6.48 \%$ & $5.64 \%$ \\
\hline $\mathrm{ARA}=4$ & & $5.64 \%$ & $4.32 \%$ & $2.76 \%$ & $7.56 \%$ & $7.08 \%$ & $6.96 \%$ & $6.96 \%$ & $4.56 \%$ & $6.36 \%$ & $6.00 \%$ \\
\hline $\mathrm{ARA}=6$ & & $5.04 \%$ & $3.84 \%$ & $0.36 \%$ & $6.48 \%$ & $4.68 \%$ & $6.72 \%$ & $5.76 \%$ & $5.40 \%$ & $6.24 \%$ & $6.36 \%$ \\
\hline \multicolumn{12}{|l|}{ Power Utility } \\
\hline $\mathrm{RRA}=2$ & & $6.12 \%$ & $4.92 \%$ & $4.92 \%$ & $8.76 \%$ & $9.24 \%$ & $7.08 \%$ & $8.04 \%$ & $3.72 \%$ & $6.48 \%$ & $5.64 \%$ \\
\hline $\mathrm{RRA}=4$ & & $5.64 \%$ & $4.32 \%$ & $2.64 \%$ & $7.56 \%$ & $6.96 \%$ & $6.96 \%$ & $6.84 \%$ & $4.56 \%$ & $6.36 \%$ & $6.00 \%$ \\
\hline $\mathrm{RRA}=6$ & & $5.04 \%$ & $3.84 \%$ & $0.00 \%$ & $6.36 \%$ & $4.20 \%$ & $6.72 \%$ & $5.76 \%$ & $5.40 \%$ & $6.24 \%$ & $6.48 \%$ \\
\hline
\end{tabular}


Table 7: Out-of-sample performance: Parametric portfolio measures and a size strategy

Entries report the performance measures (annualized Sharpe Ratio, annualized Opportunity Cost, Portfolio Turnover, annualized Return-Loss) when the benchmark set includes the Size Factor (SMB), the Barclays US Aggregate Bond Index and the 1-month LIBOR. The $p$-values of Memmel's (2003) test are also reported within parentheses; the null hypothesis is that the SR obtained from the traditional investment opportunity set is equal to that derived from the expanded set that includes commodities. The results for the opportunity cost are reported for different degrees of absolute risk aversion $(A R A=2,4,6)$ and different degrees of relative risk aversion $(\mathrm{RRA}=2,4,6)$. Investors access investment in commodities separately via first generation indices, second generation indices and third generation indices, separately. The dataset for all assets spans Jan. 1990-Sep. 2013 with the exception of DJ-UBSCI that spans Jan. 1991 to Sep.2013 due to data availability constraints. The out-of-sample analysis is conducted over the period from Jan. 2001-Sep. 2013. Panels A and B report the results for the first and second order stochastic dominance efficiency, respectively.

\begin{tabular}{|c|c|c|c|c|c|c|c|c|c|c|c|}
\hline \multicolumn{12}{|c|}{ Panel A: First Order Stochastic Dominance } \\
\hline & & \multicolumn{3}{|c|}{ 1st generation indices } & \multicolumn{4}{|c|}{ 2nd generation indices } & \multicolumn{3}{|c|}{ 3rd generation indices } \\
\hline & & $\mathbf{S \& P}$ & DJ-UBS & & & DBLCI- & & & & & \\
\hline & Benchmark set & GSCI & CI & DBLCI & JPMCCI & OY & MSDILF & MSDIL & MSDISF & MSDILS & MSDIS \\
\hline Sharpe Ratio & 0.16 & 0.61 & 0.61 & 0.65 & 0.81 & 0.88 & 0.87 & 0.84 & 0.56 & 0.77 & 0.79 \\
\hline Memmel p-value & & 0.153 & 0.121 & 0.116 & 0.030 & 0.023 & 0.026 & 0.030 & 0.120 & 0.055 & 0.032 \\
\hline PortfolioTurnover & $4.66 \%$ & $12.11 \%$ & $15.87 \%$ & $2.90 \%$ & $10.97 \%$ & $3.63 \%$ & $4.27 \%$ & $7.11 \%$ & $9.43 \%$ & $1.72 \%$ & $2.23 \%$ \\
\hline Return-Loss & & $3.88 \%$ & $4.02 \%$ & $4.63 \%$ & $7.37 \%$ & $8.34 \%$ & $8.67 \%$ & $7.84 \%$ & $5.15 \%$ & $7.47 \%$ & $8.82 \%$ \\
\hline \multicolumn{12}{|l|}{ Opportunity Cost } \\
\hline \multicolumn{12}{|l|}{ Exponential Utility } \\
\hline $\mathrm{ARA}=2$ & & $6.12 \%$ & $5.52 \%$ & $7.32 \%$ & $9.60 \%$ & $11.28 \%$ & $9.00 \%$ & $9.96 \%$ & $4.32 \%$ & $7.80 \%$ & $5.76 \%$ \\
\hline $\mathrm{ARA}=4$ & & $4.92 \%$ & $5.04 \%$ & $5.52 \%$ & $8.76 \%$ & $9.96 \%$ & $8.88 \%$ & $9.12 \%$ & $4.80 \%$ & $7.68 \%$ & $6.48 \%$ \\
\hline $\mathrm{ARA}=6$ & & $3.60 \%$ & $4.44 \%$ & $3.60 \%$ & $7.92 \%$ & $8.64 \%$ & $8.88 \%$ & $8.40 \%$ & $5.28 \%$ & $7.56 \%$ & $7.32 \%$ \\
\hline \multicolumn{12}{|l|}{ Power Utility } \\
\hline $\mathrm{RRA}=2$ & & $6.12 \%$ & $5.64 \%$ & $7.32 \%$ & $9.60 \%$ & $11.28 \%$ & $9.00 \%$ & $9.96 \%$ & $4.32 \%$ & $7.92 \%$ & $5.76 \%$ \\
\hline $\mathrm{RRA}=4$ & & $4.92 \%$ & $5.04 \%$ & $5.52 \%$ & $8.76 \%$ & $9.96 \%$ & $8.88 \%$ & $9.12 \%$ & $4.80 \%$ & $7.68 \%$ & $6.60 \%$ \\
\hline $\mathrm{RRA}=6$ & & $3.60 \%$ & $4.44 \%$ & $3.60 \%$ & $7.92 \%$ & $8.64 \%$ & $8.88 \%$ & $8.40 \%$ & $5.40 \%$ & $7.56 \%$ & $7.32 \%$ \\
\hline
\end{tabular}


Table 7: Out-of-sample performance: Parametric portfolio measures and a size strategy (cont’d)

Entries report the performance measures (annualized Sharpe Ratio, annualized Opportunity Cost, Portfolio Turnover, annualized Return-Loss) when the benchmark set includes the Size Factor (SMB), the Barclays US Aggregate Bond Index and the 1-month LIBOR. The $p$-values of Memmel's (2003) test are also reported within parentheses; the null hypothesis is that the SR obtained from the traditional investment opportunity set is equal to that derived from the expanded set that includes commodities. The results for the opportunity cost are reported for different degrees of absolute risk aversion $(A R A=2,4,6)$ and different degrees of relative risk aversion (RRA=2, 4, 6). Investors access investment in commodities separately via first generation indices, second generation indices and third generation indices, separately. The dataset for all assets spans Jan. 1990-Sep. 2013 with the exception of DJ-UBSCI that spans Jan. 1991 to Sep.2013 due to data availability constraints. The out-of-sample analysis is conducted over the period from Jan. 2001-Sep. 2013. Panels A and $\mathrm{B}$ report the results for the first and second order stochastic dominance efficiency, respectively.

\begin{tabular}{|c|c|c|c|c|c|c|c|c|c|c|c|}
\hline \multicolumn{12}{|c|}{ Panel B: Second Order Stochastic Dominance } \\
\hline & & \multicolumn{3}{|c|}{ 1st generation indices } & \multicolumn{4}{|c|}{ 2nd generation indices } & \multicolumn{3}{|c|}{ 3rd generation indices } \\
\hline & Benchmark set & $\begin{array}{c}\text { S\&P } \\
\text { GSCI } \\
\end{array}$ & $\begin{array}{c}\text { DJ-UBS } \\
\text { CI } \\
\end{array}$ & DBLCI & JPMCCI & $\begin{array}{c}\text { DBLCI- } \\
\text { OY } \\
\end{array}$ & MSDILF & MSDIL & MSDISF & MSDILS & MSDIS \\
\hline Sharpe Ratio & 0.19 & 0.22 & 0.32 & 0.40 & 0.42 & 0.56 & 0.60 & 0.52 & 0.53 & 0.77 & 0.72 \\
\hline Memmel p-value & & 0.465 & 0.363 & 0.289 & 0.269 & 0.166 & 0.166 & 0.194 & 0.194 & 0.055 & 0.083 \\
\hline PortfolioTurnover & $14.64 \%$ & $30.79 \%$ & $21.72 \%$ & $4.39 \%$ & $10.52 \%$ & $0.22 \%$ & $3.48 \%$ & $5.15 \%$ & $13.59 \%$ & $1.72 \%$ & $26.10 \%$ \\
\hline Return-Loss & & $-0.45 \%$ & $1.05 \%$ & $2.25 \%$ & $2.39 \%$ & $4.26 \%$ & $4.26 \%$ & $3.82 \%$ & $0.24 \%$ & $7.47 \%$ & $7.20 \%$ \\
\hline \multicolumn{12}{|l|}{ Opportunity Cost } \\
\hline \multicolumn{12}{|l|}{ Exponential Utility } \\
\hline $\mathrm{ARA}=2$ & & $-0.48 \%$ & $1.56 \%$ & $3.12 \%$ & $3.36 \%$ & $6.00 \%$ & $5.16 \%$ & $5.04 \%$ & $2.88 \%$ & $7.80 \%$ & $3.72 \%$ \\
\hline $\mathrm{ARA}=4$ & & $-3.24 \%$ & $0.24 \%$ & $-0.12 \%$ & $1.08 \%$ & $3.36 \%$ & $4.92 \%$ & $3.12 \%$ & $3.60 \%$ & $7.68 \%$ & $4.56 \%$ \\
\hline $\mathrm{ARA}=6$ & & $-6.24 \%$ & $-1.20 \%$ & $-3.72 \%$ & $-1.44 \%$ & $0.48 \%$ & $4.80 \%$ & $1.08 \%$ & $4.44 \%$ & $7.56 \%$ & $5.52 \%$ \\
\hline \multicolumn{12}{|l|}{ Power Utility } \\
\hline $\mathrm{RRA}=2$ & & $-0.48 \%$ & $1.56 \%$ & $3.00 \%$ & $3.24 \%$ & $6.00 \%$ & $5.16 \%$ & $5.04 \%$ & $2.88 \%$ & $7.92 \%$ & $3.72 \%$ \\
\hline $\mathrm{RRA}=4$ & & $-3.36 \%$ & $0.12 \%$ & $-0.36 \%$ & $0.96 \%$ & $3.24 \%$ & $4.92 \%$ & $3.00 \%$ & $3.60 \%$ & $7.68 \%$ & $4.56 \%$ \\
\hline $\mathrm{RRA}=6$ & & $-6.48 \%$ & $-1.44 \%$ & $-4.20 \%$ & $-1.80 \%$ & $0.12 \%$ & $4.80 \%$ & $0.84 \%$ & $4.44 \%$ & $7.56 \%$ & $5.52 \%$ \\
\hline
\end{tabular}


Table 8: Out-of-sample performance: Value and Momentum Factor in the benchmark set

Entries report the performance measures (annualized Sharpe Ratio, annualized Opportunity Cost, Portfolio Turnover, annualized Return-Loss) when the benchmark set includes the S\&P500, the HML index, the Momentum factor, the Barclays US Aggregate Bond Index and the 1-month LIBOR rate. The $p$ values of Memmel's (2003) test are also reported within parentheses; the null hypothesis is that the SR obtained from the traditional investment opportunity set is equal to that derived from the expanded set that includes commodities. The results for the opportunity cost are reported for different degrees of absolute risk aversion $(A R A=2,4,6)$ and different degrees of relative risk aversion $(R R A=2,4,6)$. Investors access investment in commodities separately via first generation indices, second generation indices and third generation indices, separately. The dataset for all assets spans Jan. 1990-Sep. 2013 with the exception of DJ-UBSCI that spans Jan. 1991 to Sep.2013 due to data availability constraints. The out-of-sample analysis is conducted over the period Jan. 2001-Sep. 2013. Panels A and B report the results for the first and second order stochastic dominance efficiency, respectively

\begin{tabular}{|c|c|c|c|c|c|c|c|c|c|c|c|}
\hline \multicolumn{12}{|c|}{ Panel A: First Order Stochastic Dominance } \\
\hline & \multicolumn{4}{|c|}{ 1st generation indices } & \multicolumn{4}{|c|}{ 2nd generation indices } & \multicolumn{3}{|c|}{ 3rd generation indices } \\
\hline & Benchmark & $\mathbf{S \& P}$ & DJ-UBS & & & DBLCI- & & & & & \\
\hline & set & GSCI & CI & DBLCI & JPMCCI & OY & MSDILF & MSDIL & MSDISF & MSDILS & MSDIS \\
\hline Sharpe Ratio & 0.146 & 0.817 & 0.853 & 0.856 & 0.856 & 1.051 & 0.752 & 0.717 & 0.671 & 0.919 & 0.691 \\
\hline Memmel p-value & & 0.017 & 0.008 & 0.014 & 0.013 & 0.002 & 0.020 & 0.025 & 0.043 & 0.007 & 0.022 \\
\hline PortfolioTurnover & $6.12 \%$ & $12.81 \%$ & $11.28 \%$ & $9.77 \%$ & $9.82 \%$ & $13.21 \%$ & $8.59 \%$ & $12.78 \%$ & $10.49 \%$ & $12.65 \%$ & $19.56 \%$ \\
\hline Return-Loss & & $9.77 \%$ & $10.24 \%$ & $10.30 \%$ & $10.39 \%$ & $12.25 \%$ & $8.80 \%$ & $8.14 \%$ & $8.29 \%$ & $10.98 \%$ & $7.30 \%$ \\
\hline \multicolumn{12}{|l|}{ Opportunity Cost } \\
\hline \multicolumn{12}{|l|}{ Exponential Utility } \\
\hline $\mathrm{ARA}=2$ & & $4.56 \%$ & $4.92 \%$ & $4.92 \%$ & $4.92 \%$ & $6.72 \%$ & $4.56 \%$ & $4.32 \%$ & $3.48 \%$ & $5.28 \%$ & $4.20 \%$ \\
\hline $\mathrm{ARA}=4$ & & $5.64 \%$ & $6.00 \%$ & $6.00 \%$ & $6.00 \%$ & $7.68 \%$ & $5.64 \%$ & $5.28 \%$ & $4.56 \%$ & $6.36 \%$ & $5.16 \%$ \\
\hline $\mathrm{ARA}=6$ & & $6.84 \%$ & $7.08 \%$ & $7.08 \%$ & $7.08 \%$ & $8.76 \%$ & $6.60 \%$ & $6.36 \%$ & $5.76 \%$ & $7.44 \%$ & $6.24 \%$ \\
\hline \multicolumn{12}{|l|}{ Power Utility } \\
\hline $\mathrm{RRA}=2$ & & $4.56 \%$ & $4.92 \%$ & $4.92 \%$ & $4.92 \%$ & $6.72 \%$ & $4.56 \%$ & $4.32 \%$ & $3.48 \%$ & $5.28 \%$ & $4.20 \%$ \\
\hline $\mathrm{RRA}=4$ & & $5.64 \%$ & $6.00 \%$ & $6.00 \%$ & $6.00 \%$ & $7.68 \%$ & $5.64 \%$ & $5.28 \%$ & $4.56 \%$ & $6.36 \%$ & $5.16 \%$ \\
\hline $\mathrm{RRA}=6$ & & $6.84 \%$ & $7.08 \%$ & $7.20 \%$ & $7.08 \%$ & $8.76 \%$ & $6.60 \%$ & $6.36 \%$ & $5.76 \%$ & $7.44 \%$ & $6.24 \%$ \\
\hline
\end{tabular}


Table 8: Out-of-sample performance: Value and Momentum Factor in the benchmark set (cont'd)

Entries report the performance measures (annualized Sharpe Ratio, annualized Opportunity Cost, Portfolio Turnover, annualized Return-Loss) when the benchmark set includes the S\&P500, the HML index, the Momentum factor, the Barclays US Aggregate Bond Index and the 1-month LIBOR rate. The pvalues of Memmel's (2003) test are also reported within parentheses; the null hypothesis is that the SR obtained from the traditional investment opportunity set is equal to that derived from the expanded set that includes commodities. The results for the opportunity cost are reported for different degrees of absolute risk aversion (ARA=2, 4, 6) and different degrees of relative risk aversion (RRA=2, 4, 6). Investors access investment in commodities separately via first generation indices, second generation indices and third generation indices, separately. The dataset for all assets spans Jan. 1990-Sep. 2013 with the exception of DJ-UBSCI that spans Jan. 1991 to Sep.2013 due to data availability constraints. The out-of-sample analysis is conducted over the period from Jan. 2001Sep. 2013. Panels A and B report the results for the first and second order stochastic dominance efficiency, respectively.

\begin{tabular}{|c|c|c|c|c|c|c|c|c|c|c|c|}
\hline & \multicolumn{4}{|c|}{ 1st generation indices } & \multicolumn{4}{|c|}{ 2nd generation indices } & \multicolumn{3}{|c|}{ 3rd generation indices } \\
\hline & Benchmark & S\&P & DJ-UBS & & & DBLCI- & & & & & \\
\hline & set & GSCI & CI & DBLCI & JPMCCI & OY & MSDILF & MSDIL & MSDISF & MSDILS & MSDIS \\
\hline Sharpe Ratio & 0.409 & 0.677 & 0.811 & 0.765 & 0.743 & 0.786 & 0.984 & 0.776 & 0.679 & 0.929 & 0.744 \\
\hline Memmel p-value & & 0.184 & 0.087 & 0.121 & 0.154 & 0.127 & 0.039 & 0.126 & 0.204 & 0.062 & 0.143 \\
\hline PortfolioTurnover & $16.22 \%$ & $32.83 \%$ & $24.68 \%$ & $10.55 \%$ & $9.33 \%$ & $14.94 \%$ & $8.92 \%$ & $22.47 \%$ & $33.34 \%$ & $8.70 \%$ & $44.03 \%$ \\
\hline Return-Loss & & $2.45 \%$ & $4.13 \%$ & $4.28 \%$ & $4.02 \%$ & $3.96 \%$ & $6.10 \%$ & $3.42 \%$ & $5.03 \%$ & $5.76 \%$ & $2.74 \%$ \\
\hline \multicolumn{12}{|l|}{ Opportunity Cost } \\
\hline \multicolumn{12}{|l|}{ Exponential Utility } \\
\hline $\mathrm{ARA}=2$ & & $0.48 \%$ & $1.20 \%$ & $1.20 \%$ & $1.32 \%$ & $1.68 \%$ & $2.40 \%$ & $1.68 \%$ & $-1.32 \%$ & $1.92 \%$ & $0.48 \%$ \\
\hline $\mathrm{ARA}=4$ & & $0.96 \%$ & $1.56 \%$ & $1.56 \%$ & $1.68 \%$ & $2.04 \%$ & $2.76 \%$ & $2.04 \%$ & $-0.72 \%$ & $2.40 \%$ & $0.96 \%$ \\
\hline $\mathrm{ARA}=6$ & & $1.32 \%$ & $2.04 \%$ & $1.92 \%$ & $1.92 \%$ & $2.28 \%$ & $3.12 \%$ & $2.40 \%$ & $0.00 \%$ & $2.76 \%$ & $1.44 \%$ \\
\hline \multicolumn{12}{|l|}{ Power Utility } \\
\hline $\mathrm{RRA}=2$ & & $0.48 \%$ & $1.20 \%$ & $1.20 \%$ & $1.32 \%$ & $1.68 \%$ & $2.40 \%$ & $1.68 \%$ & $-1.32 \%$ & $1.92 \%$ & $0.48 \%$ \\
\hline $\mathrm{RRA}=4$ & & $0.96 \%$ & $1.56 \%$ & $1.56 \%$ & $1.68 \%$ & $2.04 \%$ & $2.76 \%$ & $2.04 \%$ & $-0.72 \%$ & $2.40 \%$ & $0.96 \%$ \\
\hline $\mathrm{RRA}=6$ & & $1.32 \%$ & $2.04 \%$ & $1.92 \%$ & $1.92 \%$ & $2.28 \%$ & $3.12 \%$ & $2.40 \%$ & $0.00 \%$ & $2.76 \%$ & $1.44 \%$ \\
\hline
\end{tabular}


Table 9: Out-of-sample performance: Alternative equity indices in the benchmark asset universe

Entries report the performance measures (annualized Sharpe Ratio, annualized Opportunity Cost, Portfolio Turnover, annualized Return-Loss) when the benchmark set includes the Russell 2000 Index, the Vanguard value index, Vanguard small cap index, the Barclays US Aggregate Bond Index and the 1month LIBOR rate. The $p$-values of Memmel's (2003) test are also reported within parentheses; the null hypothesis is that the SR obtained from the traditional investment opportunity set is equal to that derived from the expanded set that includes commodities. The results for the opportunity cost are reported for different degrees of absolute risk aversion $(A R A=2,4,6)$ and different degrees of relative risk aversion $(R R A=2,4,6)$. Investors access investment in commodities separately via first generation indices, second generation indices and third generation indices, separately. The dataset for all assets spans Jan. 1990-Sep. 2013 with the exception of DJ-UBSCI that covers Jan. 1991 to Sep.2013 due to data availability constraints. The out-of-sample analysis is conducted over the period Jan. 2001-Sep. 2013. Panels A and B report the results for the first and second order stochastic dominance efficiency, respectively.

\begin{tabular}{|c|c|c|c|c|c|c|c|c|c|c|c|}
\hline & \multicolumn{4}{|c|}{ 1st generation indices } & \multicolumn{4}{|c|}{ 2nd generation indices } & \multicolumn{3}{|c|}{ 3rd generation indices } \\
\hline & Benchmark & S\&P & DJ-UBS & & & DBLCI- & & & & & \\
\hline & set & GSCI & CI & DBLCI & JPMCCI & $\mathbf{O Y}$ & MSDILF & MSDIL & MSDISF & MSDILS & MSDIS \\
\hline Sharpe Ratio & 0.387 & 0.447 & 0.477 & 0.461 & 0.533 & 0.644 & 0.598 & 0.678 & 0.492 & 0.627 & 0.420 \\
\hline Memmel p-value & & 0.392 & 0.333 & 0.383 & 0.251 & 0.103 & 0.209 & 0.135 & 0.330 & 0.145 & 0.441 \\
\hline PortfolioTurnover & $8.58 \%$ & $13.21 \%$ & $18.75 \%$ & $14.07 \%$ & $10.47 \%$ & $21.15 \%$ & $11.62 \%$ & $10.71 \%$ & $14.19 \%$ & $8.80 \%$ & $5.44 \%$ \\
\hline Return-Loss & & $1.25 \%$ & $1.87 \%$ & $2.24 \%$ & $3.36 \%$ & $4.86 \%$ & $5.86 \%$ & $6.91 \%$ & $2.93 \%$ & $6.02 \%$ & $1.90 \%$ \\
\hline \multicolumn{12}{|l|}{ Opportunity Cost } \\
\hline \multicolumn{12}{|l|}{ Exponential Utility } \\
\hline $\mathrm{ARA}=2$ & & $1.20 \%$ & $1.44 \%$ & $0.84 \%$ & $2.40 \%$ & $4.44 \%$ & $1.68 \%$ & $3.60 \%$ & $1.20 \%$ & $2.88 \%$ & $0.24 \%$ \\
\hline $\mathrm{ARA}=4$ & & $1.92 \%$ & $2.88 \%$ & $2.76 \%$ & $3.84 \%$ & $5.52 \%$ & $4.56 \%$ & $5.88 \%$ & $3.48 \%$ & $5.28 \%$ & $2.40 \%$ \\
\hline $\mathrm{ARA}=6$ & & $2.76 \%$ & $4.56 \%$ & $4.80 \%$ & $5.40 \%$ & $6.72 \%$ & $7.56 \%$ & $8.28 \%$ & $6.00 \%$ & $7.80 \%$ & $4.80 \%$ \\
\hline \multicolumn{12}{|l|}{ Power Utility } \\
\hline $\mathrm{RRA}=2$ & & $1.20 \%$ & $1.44 \%$ & $0.84 \%$ & $2.40 \%$ & $4.44 \%$ & $1.80 \%$ & $3.60 \%$ & $1.20 \%$ & $2.88 \%$ & $0.24 \%$ \\
\hline $\mathrm{RRA}=4$ & & $2.04 \%$ & $3.00 \%$ & $2.88 \%$ & $3.96 \%$ & $5.52 \%$ & $4.68 \%$ & $6.00 \%$ & $3.60 \%$ & $5.40 \%$ & $2.52 \%$ \\
\hline $\mathrm{RRA}=6$ & & $3.00 \%$ & $4.68 \%$ & $5.04 \%$ & $5.64 \%$ & $6.84 \%$ & $7.80 \%$ & $8.52 \%$ & $6.12 \%$ & $8.04 \%$ & $5.04 \%$ \\
\hline
\end{tabular}


Table 9: Out-of-sample performance: Alternative equity indices in the benchmark asset universe (cont'd)

Entries report the performance measures (annualized Sharpe Ratio, annualized Opportunity Cost, Portfolio Turnover, annualized Return-Loss) when the benchmark set includes the Russell 2000 Index, the Vanguard value index, Vanguard small cap index, the Barclays US Aggregate Bond Index and the 1month LIBOR rate. The $p$-values of Memmel's (2003) test are also reported within parentheses; the null hypothesis is that the SR obtained from the traditional investment opportunity set is equal to that derived from the expanded set that includes commodities. The results for the opportunity cost are reported for different degrees of absolute risk aversion $(A R A=2,4,6)$ and different degrees of relative risk aversion $(R R A=2,4,6)$. Investors access investment in commodities separately via first generation indices, second generation indices and third generation indices, separately. The dataset for all assets spans Jan. 1990-Sep. 2013 with the exception of DJ-UBSCI that covers Jan. 1991 to Sep.2013 due to data availability constraints. The out-of-sample analysis is conducted over the period Jan. 2001-Sep. 2013. Panels A and B report the results for the first and second order stochastic dominance efficiency, respectively.

Panel B: Second Order Stochastic Dominance

\begin{tabular}{|c|c|c|c|c|c|c|c|c|c|c|c|}
\hline & \multicolumn{4}{|c|}{ 1st generation indices } & \multicolumn{4}{|c|}{ 2nd generation indices } & \multicolumn{3}{|c|}{ 3rd generation indices } \\
\hline & \multirow{2}{*}{$\begin{array}{c}\text { Benchmark } \\
\text { set }\end{array}$} & S\&P & DJ-UBS & & & DBLCI- & & & & & \\
\hline & & GSCI & CI & DBLCI & JPMCCI & OY & MSDILF & MSDIL & MSDISF & MSDILS & MSDIS \\
\hline Sharpe Ratio & 0.269 & 0.234 & 0.448 & 0.570 & 0.564 & 0.570 & 0.788 & 0.892 & 0.863 & 0.732 & 0.549 \\
\hline Memmel p-value & & 0.553 & 0.263 & 0.131 & 0.150 & 0.131 & 0.040 & 0.024 & 0.026 & 0.079 & 0.151 \\
\hline PortfolioTurnover & $13.44 \%$ & $31.22 \%$ & $28.26 \%$ & $24.76 \%$ & $9.10 \%$ & $24.76 \%$ & $7.01 \%$ & $15.25 \%$ & $30.68 \%$ & $7.33 \%$ & $46.79 \%$ \\
\hline Return-Loss & & $-0.64 \%$ & $4.11 \%$ & $5.35 \%$ & $7.33 \%$ & $5.35 \%$ & $12.08 \%$ & $12.69 \%$ & $14.00 \%$ & $11.09 \%$ & $4.90 \%$ \\
\hline Opportunity Cost & & & & & & & & & & & \\
\hline Exponential Utility & & & & & & & & & & & \\
\hline $\mathrm{ARA}=2$ & & $-0.24 \%$ & $1.44 \%$ & $3.72 \%$ & $2.64 \%$ & $3.72 \%$ & $3.84 \%$ & $5.64 \%$ & $2.28 \%$ & $3.36 \%$ & $2.64 \%$ \\
\hline $\mathrm{ARA}=4$ & & $1.68 \%$ & $3.96 \%$ & $5.40 \%$ & $5.04 \%$ & $5.40 \%$ & $6.48 \%$ & $8.04 \%$ & $5.28 \%$ & $6.00 \%$ & $5.04 \%$ \\
\hline $\mathrm{ARA}=6$ & & $3.60 \%$ & $6.60 \%$ & $7.20 \%$ & $7.56 \%$ & $7.20 \%$ & $9.24 \%$ & $10.68 \%$ & $8.52 \%$ & $8.88 \%$ & $7.68 \%$ \\
\hline Power Utility & & & & & & & & & & & \\
\hline $\mathrm{RRA}=2$ & & $-0.24 \%$ & $1.44 \%$ & $3.72 \%$ & $2.64 \%$ & $3.72 \%$ & $3.84 \%$ & $5.76 \%$ & $2.40 \%$ & $3.36 \%$ & $2.76 \%$ \\
\hline $\mathrm{RRA}=4$ & & $1.68 \%$ & $4.08 \%$ & $5.52 \%$ & $5.04 \%$ & $5.52 \%$ & $6.60 \%$ & $8.16 \%$ & $5.40 \%$ & $6.12 \%$ & $5.16 \%$ \\
\hline $\mathrm{RRA}=6$ & & $3.84 \%$ & $6.84 \%$ & $7.32 \%$ & $7.68 \%$ & $7.32 \%$ & $9.48 \%$ & $10.92 \%$ & $8.76 \%$ & $9.00 \%$ & $7.92 \%$ \\
\hline
\end{tabular}




\section{Table 10: Testing for market integration}

Entries report coefficients of predictor variables. Predictive regressions are run to implement Campbell and Hamao (1992) test for market integration. Dependent variables for the regressions are the excess returns on commodity, equity and bond indices. The independent variables are the instrumental variables lagged one month: the dividend yield, yield on the three-month Treasury bills, the junk bond premium (or default spread) defined as the excess of the yield on long-term BAA corporate bonds rated by Moody's over the yield on AAA-rated bonds, the term spread defined as the difference between the Aaa yield and the one-month bill rate, the Industrial Production growth, the money supply growth, and the growth in the Baltic Dry Index. A constant term is included in all regressions. The coefficient estimates, the respective $t$-statistics, the Adjusted $\mathrm{R}^{2}$, the $F$-statistic and the respective $p$-values are reported. The dataset spans 1999-2013. One and two asterisks indicate that the coefficient estimates are statistically significant different from zero at $10 \%$ and $5 \%$ significance level, respectively.

\begin{tabular}{|c|c|c|c|c|c|c|c|c|c|c|c|c|}
\hline Index & & Intercept & T-bill & Dividend Yield & Junk bond yield & Term Spread & Money Growth & Industrial Production growth & Baltic Dry Index & Adj R squared & F-statistic & p-value \\
\hline \multirow[t]{2}{*}{ S\&P GSCI } & & 0.180 & -0.008 & -0.060 & 0.002 & -0.008 & -0.850 & 0.687 & 0.023 & $1.77 \%$ & 1.449 & 0.189 \\
\hline & $t$-stat & (1.574) & $(-1.104)$ & $(-1.495)$ & $(0.128)$ & $(-1.005)$ & $(-1.559)$ & $(0.815)$ & $(0.962)$ & & & \\
\hline \multirow[t]{2}{*}{ DJ -UBS CI } & & 0.057 & -0.001 & -0.022 & 0.005 & -0.003 & -0.266 & 0.710 & 0.012 & $-1.14 \%$ & 0.719 & 0.656 \\
\hline & t-stat & $(0.680)$ & $(-0.192)$ & $(-0.762)$ & $(0.429)$ & $(-0.430)$ & $(-0.663)$ & $(1.143)$ & $(0.696)$ & & & \\
\hline \multirow[t]{2}{*}{ DBLCI } & & 0.119 & -0.003 & -0.039 & 0.000 & -0.006 & -0.500 & 0.716 & 0.021 & $0.85 \%$ & 1.213 & 0.298 \\
\hline & t-stat & (1.112) & $(-0.489)$ & $(-1.032)$ & $(0.022)$ & $(-0.712)$ & $(-0.979)$ & $(0.906)$ & $(0.955)$ & & & \\
\hline \multirow[t]{2}{*}{ JPMCCI } & & 0.088 & -0.004 & -0.025 & 0.005 & -0.006 & -0.555 & 0.668 & 0.019 & $0.72 \%$ & 1.181 & 0.317 \\
\hline & $t$-stat & (0.992) & $(-0.700)$ & $(-0.815)$ & $(0.386)$ & $(-0.874)$ & $(-1.308)$ & (1.018) & (1.054) & & & \\
\hline \multirow[t]{2}{*}{ DBLCI-OY } & & 0.073 & -0.002 & -0.021 & 0.001 & -0.004 & -0.387 & 0.669 & 0.018 & $-0.28 \%$ & 0.930 & 0.485 \\
\hline & t-stat & (0.769) & $(-0.297)$ & $(-0.632)$ & $(0.096)$ & $(-0.559)$ & $(-0.852)$ & $(0.952)$ & (0.913) & & & \\
\hline \multirow[t]{2}{*}{ MSDILF } & & 0.026 & 0.001 & -0.013 & -0.001 & 0.001 & -0.125 & 0.370 & -0.017 & $-1.19 \%$ & 0.707 & 0.666 \\
\hline & $t$-stat & $(0.424)$ & (0.338) & $(-0.614)$ & $(-0.145)$ & $(0.248)$ & $(-0.431)$ & (0.827) & $(-1.371)$ & & & \\
\hline \multirow[t]{2}{*}{ MSDILF } & & 0.100 & -0.003 & -0.035 & 0.008 & -0.005 & -0.433 & 0.664 & 0.012 & $-0.59 \%$ & 0.853 & 0.545 \\
\hline & t-stat & (1.120) & $(-0.594)$ & $(-1.135)$ & (0.597) & $(-0.737)$ & $(-1.021)$ & (1.014) & $(0.636)$ & & & \\
\hline \multirow[t]{2}{*}{ MSDISF } & & 0.008 & 0.001 & -0.005 & -0.007 & 0.001 & 0.088 & -0.203 & -0.002 & $-1.28 \%$ & 0.687 & 0.683 \\
\hline & t-stat & $(0.259)$ & $(0.285)$ & $(-0.452)$ & $(-1.523)$ & $(0.637)$ & (0.634) & $(-0.944)$ & $(-0.308)$ & & & \\
\hline \multirow[t]{2}{*}{ MSDILS } & & 0.030 & 0.002 & -0.016 & -0.008 & 0.003 & -0.034 & 0.163 & -0.019 & $0.08 \%$ & 1.020 & 0.419 \\
\hline & $t$-stat & (0.493) & $(0.510)$ & $(-0.751)$ & $(-0.898)$ & $(0.566)$ & $(-0.119)$ & $(0.366)$ & $(-1.546)$ & & & \\
\hline \multirow[t]{2}{*}{ MSDIS } & & -0.061 & 0.004 & 0.018 & -0.005 & 0.003 & 0.532 & -0.647 & -0.011 & $-0.98 \%$ & 0.758 & 0.624 \\
\hline & t-stat & $(-0.725)$ & (0.649) & (0.599) & $(-0.426)$ & $(0.553)$ & (1.322) & $(-1.040)$ & $(-0.623)$ & & & \\
\hline \multirow[t]{2}{*}{ S\&P 500} & & $0.137^{*}$ & $-0.012 * *$ & -0.032 & 0.008 & $-0.012 * *$ & -0.217 & 0.119 & $0.031^{* *}$ & $3.24 \%$ & 1.833 & 0.084 \\
\hline & $t$-stat & (1.825) & $(-2.542)$ & $(-1.213)$ & (0.749) & $(-2.139)$ & $(-0.606)$ & $(0.215)$ & (1.997) & & & \\
\hline \multicolumn{2}{|c|}{ Barclays Bond Index } & $-0.042^{* *}$ & $0.003^{* *}$ & $0.010^{*}$ & -0.002 & $0.004 * *$ & 0.123 & 0.103 & -0.001 & 0.069 & 2.845 & 0.008 \\
\hline & $t$-stat & $(-2.471)$ & (2.773) & $(1.692)$ & $(-0.668)$ & (3.372) & $(1.541)$ & $(0.834)$ & $(-0.321)$ & & & \\
\hline
\end{tabular}

